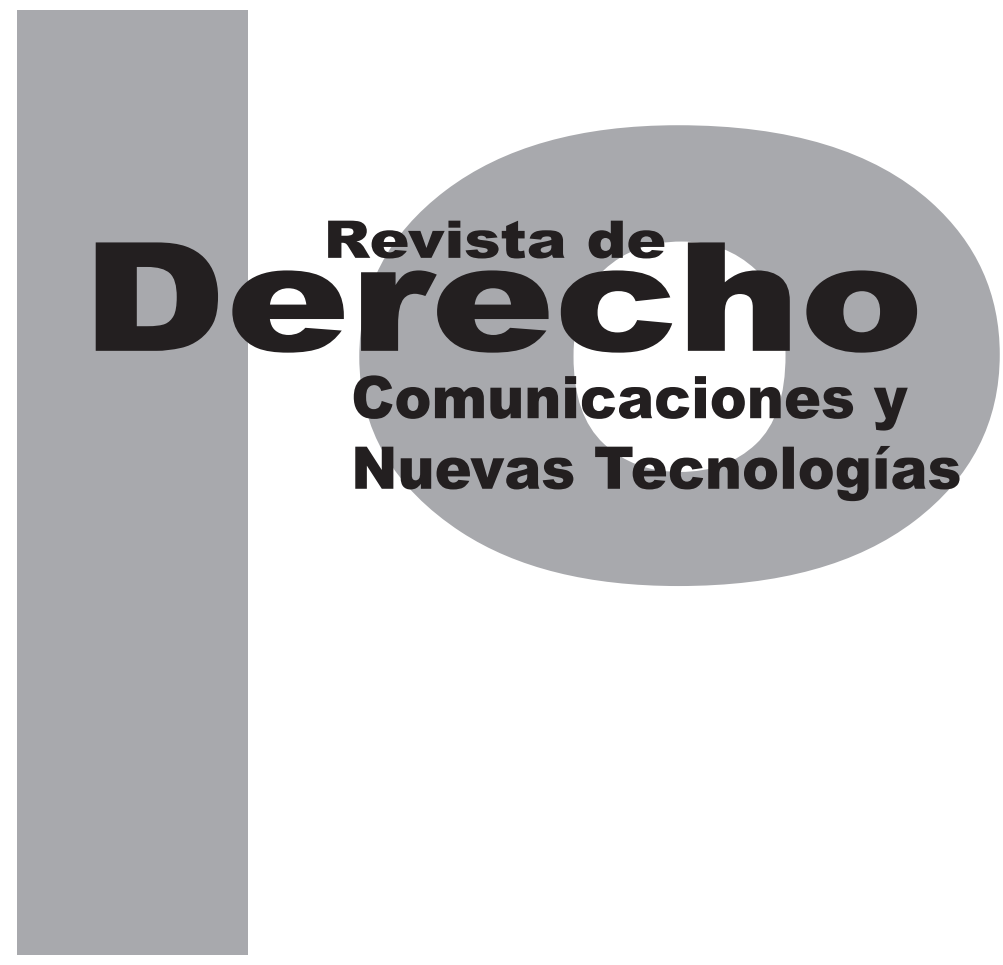

\title{
EL DERECHO AL OLVIDO EN INTERNET A LA LUZ DE LA PROPUESTA DE REGLAMENTO GENERAL DE PROTECCIÓN DE DATOS PERSONALES DE LA UNIÓN EUROPEA
}

\author{
Antonio Troncoso ReIgAdA
}

Universidad de los Andes

Facultad de Derecho

Revista de Derecho, comunicaciones y Nuevas Tecnologías

N. ${ }^{\circ}$, Diciembre de 2012. ISSN 1909-7786 


\title{
El derecho al olvido en Internet a la luz de la propuesta de reglamento general de protec- ción de datos personales de la Unión Europea
}

\author{
Antonio Troncoso Reigada*
}

\section{RESUMEN}

La Comisión Europea aprobó una propuesta de Reglamento General de Protección de Datos, que derogará la actual Directiva 95/46/CE. Este estudio analiza la regulación del derecho al olvido en Internet, que hace recaer la responsabilidad de garantizarlo en quien haya publicado los datos personales y no en los buscadores. Así, no parece razonable considerar el derecho al olvido en Internet como una obligación que descansa principalmente en la responsabilidad de los motores de búsqueda; olvidando otras responsabilidades mucho más graves en las que incurre el responsable de la publicación inicial de la web máster, como, por ejemplo, la Administración cuando publica boletines oficiales y páginas web institucionales en abierto en Internet, $y$ haciendo caso omiso de las propias características de los tratamientos que llevan a cabo los motores de búsqueda - de carácter fundamentalmente técnico-. Finalmente, analiza los
The European Commission has adopted a Proposal for a General Data Protection Regulation, which will repeal the actual Directive 95/46/EC. This study analyzes the regulation of the right to be forgotten in the online environment, which places the responsability for ensuring this right in who has published personal data and not in the search engines. Thus, it is unreasonable to consider the right to be forgotten as an obligation that rests primarily the responsibility on the search engines, forgetting other more relevant responsibilities incurred by the responsible for the initial publication of such web-master -for example, the Administration when publish institutional websites open in Internet- and ignoring the characteristics of the treatments carried out by the search engines, primarily technical. Finally this study analyzes the limits of the right to protection of personal data regarding to the freedom of information. 
límites al derecho a la protección de datos personales que la propuesta de Reglamento incorpora para garantizar la libertad de información y de expresión.

Palabras clave: derecho al olvido, libertad de información, derecho a la protección de datos personales, derecho a la privacidad, Reglamento General de Protección de Datos.
KEYWORDS: the right to be forgotten in the online environment, freedom of information, right to protection of personal data, right to privacy, General Data Protection Regulation. 


\section{SUMARIO}

I. LA PROPUESTA DE NUEVO MARCO NORMATIVO EUROPEO PARA LA PROTECCIÓN DE LOS DATOS PERSONALES Y LOS DERECHOS DE ACCESO, RECTIFICACIÓN Y CANCELACIÓN. - II. EL DERECHO AL OLVIDO EN INTERNET: LAS OBLIGACIONES DEL RESPONSABLE PRINCIPAL DE LA WEB MÁSTER QUE HA HECHO PÚBLICO LOS DATOS Y LA IMPOSIBILIDAD DE EJERCER EL DERECHO DE OPOSICIÓN ANTE LOS BUSCADORES. - III. LOS LÍMITES AL DERECHO AL OLVIDO: LA PUBLICACIÓN DE LOS MEDIOS DE COMUNICACIÓN EN INTERNET Y EL EJERCICIO DE LA LIBERTAD DE EXPRESIÓN 


\section{LA PROPUESTA DE NUEVO MARCO NORMATIVO EUROPEO PARA LA PRO- TECCIÓN DE LOS DATOS PERSONALES $Y$ LOS DERECHOS DE ACCESO, RECTIFI- CACIÓN Y CANCELACIÓN}

La Comisión Europea está impulsando la configuración de un nuevo marco jurídico europeo para la protección de los datos personales en la Unión Europea ${ }^{1}$, a través de la aprobación el 25 de enero de 2012 de una propuesta de Reglamento del Parlamento Europeo y del Consejo, relativo a la protección de las personas físicas en lo que respecta al tratamiento de los datos personales y a la libre circulación de estos datos - un Reglamento General de Protección de Datos-, que derogará la actual Directiva 95/46/ $\mathrm{CE}^{-2}$ y de una propuesta de Directiva del Parlamento Europeo y del Consejo relativa a la protección de las personas físicas en lo que respecta al tratamiento de datos personales por parte de las autoridades competentes para fines de prevención, investigación, detección o enjuiciamiento de infracciones penales o de ejecución de sanciones penales, y la libre circulación de dichos datos ${ }^{3}$. La propuesta de un nuevo marco jurídico europeo busca ser una respuesta a los

1 Ver más información en: Comunicación de la Comisión "La protección de la privacidad en un mundo interconectado. Un Marco Europeo de Protección de Datos para el siglo XXI", COM (2012) 9 final. Esta cuestión la hemos abordado con más extensión en Troncoso (2012, pp. 25-160). Este trabajo se enmarca dentro del Proyecto de investigación "Transparencia administrativa y protección de datos personales" -DER2012-39629- del Ministerio de Economía y Competitividad.

2 Cfr. sobre la Directiva 95/46/CE del Parlamento Europeo y del Consejo, relativa a la protección de las personas físicas en lo que respecta al tratamiento de datos personales y a la libre circulación de estos datos, entre otros: Heredero (1998); Arenas (2006, pp. 191-376); Guerrero (2006, pp. 55-134); Téllez (2002, pp. 329-349). cambios que se han producido en las tecnologías de la información y la comunicación desde la aprobación de la Directiva de 1995, que no alcanza a regular el desarrollo y la rapidez de Internet y los tratamientos de datos personales que llevan a cabo los motores de búsqueda, afrontando los riesgos significativos que presentan las actividades en línea ${ }^{4}$. La Comisión Europea considera que los problemas que plantea para la protección de los datos personales un mundo globalizado e interconectado -donde usuarios y proveedores de servicios se encuentran frecuentemente en países y continentes distintos y donde no existen unos estándares internacionales en este ámbito- se resuelven mejor a nivel europeo. La propuesta de Reglamento permite una protección más efectiva de los ciudadanos europeos frente a los tratamientos de datos a escala internacional, como los que realizan los potentes motores de búsqueda, dando a las personas más instrumentos para el control sobre su información personal.

En esta dirección, la propuesta de Reglamento aborda con precisión cuestiones como el ámbito de aplicación territorial, que resuelve la problemática de jurisdicción y de ley aplicable que plantean las corporaciones internacionales que ofrecen servicios de tratamiento de datos -redes sociales virtuales, motores de búsqueda, servicios de computación en nube- y que tienen su sede fuera de la Unión Europea. Igu-

4 La Comisión señala la existencia de una percepción generalizada entre la opinión pública acerca de la existencia de riesgos significativos para la protección de las personas relacionados especialmente con las actividades en línea -Considerando 7 y Eurobarómetro especial (EB) 359, Data Protection and Electronic Identity in the EU (Protección de datos e identidad electrónica en la UE, 2011), en http://ec.europa.eu/ public_opinion/archives/ebs/ebs_359_en.pdf.-. 
almente, regula con rigor la transparencia de la información y el derecho al olvido en Internet el deseo de "borrar el rastro en Internet"-, haciendo recaer la responsabilidad de garantizarlo en quien haya publicado los datos personales y no en los buscadores; al mismo tiempo que incorpora límites al derecho a la protección de datos personales para garantizar la libertad de información y de expresión.

Así, la propuesta de Reglamento mejora el ejercicio de los derechos de acceso, rectificación y cancelación de datos personales a nivel europeo, fijando plazos de respuesta a las peticiones de las personas afectadas, autorizando el ejercicio de estos derechos por vía electrónica y obligando a motivar las denegaciones (arts. 11-15) ${ }^{5}$. La normativa española ya es bastante completa en relación con el ejercicio de estos derechos, si bien, al igual que en el caso del principio de información, cuando el interesado solicite el ejercicio del derecho de acceso, el responsable tendrá ahora que facilitar información sobre el plazo durante el cual se conservarán los datos personales - plazo para la supresión que también está sometido a una obligación de documentación en virtud del art. 28.2.g y, que, por tanto, está a disposición de la autoridad de control- y el derecho a presentar una reclamación ante la autoridad de control. En general, la regulación de los derechos del interesado, especialmente en lo relativo a la información al inte-

5 También se establece en el art. 13 unos derechos en relación con el destinatario, que consiste en la obligación del responsable del tratamiento de informar a los destinatarios a los que haya comunicado sus datos -incluyendo al encargado del tratamiento-, de cualquier rectificación o supresión de datos en virtud del ejercicio de los derechos de los interesados, lo que tiene gran importancia en relación con el derecho al olvido en Internet. resado y al ejercicio del derecho de acceso, está presidido por la obligación del responsable del tratamiento de aplicar políticas transparentes y fácilmente accesibles en lo que respeta al tratamiento de datos personales y al ejercicio de los derechos de los interesados ${ }^{6}$. El principio de transparencia exige, por tanto, que toda información dirigida al público o al interesado sea de fácil acceso y comprensión, y que se utilice un lenguaje sencillo y claro ${ }^{7}$ Esta obligación de ofrecer información transparente, accesible y fácil de comprender se encuentra inspirada en la Resolución de Madrid relativa a estándares internacionales sobre protección de datos personales y privacidad ${ }^{8}$. Sin embargo, esta cuestión no es abordada por el art. 8 de la Carta de los Derechos Fundamentales de la Unión Europea ${ }^{9}$.

6 Tanto la información como el ejercicio de los derechos son gratuitos, salvo que la solicitud sea claramente excesiva por su carácter repetitivo, que justifique, en su caso la aplicación de una tasa, asumiendo el responsable la carga de la prueba de la demostración del carácter excesivo de la solicitud. Parece más acertada esta regulación que la normativa española que prohíbe el ejercicio del derecho de acceso a intervalos inferiores a doce meses, salvo que el interesado acredite un interés legítimo -art. 15 LOPD-, haciendo recaer sobre éste la carga de la prueba

7 Esto es especialmente importante en el caso de los niños que merecen una protección específica, por lo que cualquier información y comunicación que les afecte debe ofrecerse en un lenguaje claro y llano que puedan comprender con facilidad. Este principio de transparencia es especialmente aplicable a la publicidad en línea, donde la proliferación de agentes y la complejidad tecnológica hace que resulte difícil para el interesado saber y comprender si se están recogiendo datos personales que le conciernen, por quién y con qué finalidad -Considerando 46 de la propuesta de Reglamento-.

Esta obligación de transparencia también se ha incorporado al art. 13.3 de la propuesta de Reglamento relativa a una normativa común de compraventa europea (COM (2011) 635 final).

9 El art. 8 de la Carta no menciona el principio de transparencia ni tampoco hace referencia a la necesaria información al interesado. Se limita a reconocer que "toda persona tiene derecho a acceder a los datos recogidos que la conciernan y a obtener su rectificación" (art. 8.2), de manera que ni siquiera reconoce el derecho de cancelación. 
II. EL DERECHO AL OLVIDO EN INTERNET: LAS OBLIGACIONES DEL RESPONSABLE PRINCIPAL DE LA WEB MÁSTER QUE HA HECHO PÚBLICO LOS DATOS Y LA IMPOSIBILIDAD DE EJERCER EL DERECHO DE OPOSICIÓN ANTE LOS BUSCADORES

Especial mención merece la regulación que la propuesta de Reglamento hace del derecho de rectificación y de supresión o cancelación (art. 16-18) ${ }^{10}$, al abordar, de manera ambiciosa, el derecho al olvido en Internet, que no es más que la aplicación en Internet de los derechos de oposición y cancelación, una cuestión que ha suscitado hasta ahora una cierta controversia. La Comisión busca dar respuesta a los desafíos que plantean los tratamientos de datos personales en redes sociales, motores de búsqueda, o servicios de computación en nube -por ejemplo, para compartir fotografías- y las dificultades que se presentan para que los interesados mantengan un control efectivo sobre sus datos personales - para que puedan recuperar o borrar sus datos personales de estos prestatarios de servicios en línea-. Frente a este problema, la propuesta de Reglamento reconoce el derecho

10 Destaca la previsión del derecho de rectificación que incluye el derecho del interesado a que se completen los datos personales cuando resulten incompletos, en particular, mediante una declaración rectificativa adicional, algo especialmente importante en el ámbito de las Administraciones Públicas, porque el mantenimiento de datos erróneos o incompletos puede dificultar el ejercicio de derechos fundamentales o la percepción de prestaciones sociales. La propuesta de reglamento establece el derecho a que se restrinja el tratamiento de datos en algunos supuestos, evitando la ambigüedad del término bloqueo. Asimismo, se especifican los límites a la supresión cuando es necesaria la conservación de los datos por motivos de salud pública o para fines de investigación histórica, estadística o científica. La propuesta de Reglamento incluye también una interesante regulación sobre la conservación de datos a efectos probatorios (art. 17). al olvido en Internet, atribuyendo al interesado el derecho a que el responsable suprima los datos personales que le conciernan y se abstenga de darles más difusión cuando los datos ya no sean necesarios en relación con los fines, haya expirado el plazo de conservación autorizado se haya cumplido el periodo de almacenamiento de datos-, el interesado retire el consentimiento o se oponga al tratamiento (art. 17.1).

De esta forma, se reconoce expresamente el derecho de los usuarios a exigir a los proveedores de estos servicios de Internet que borren completamente sus datos personales - por ejemplo, sus fotos- cuando el cliente se dé de baja en el servicio o cuando dejen de ser necesarios para los fines para los que se recabaron ${ }^{11}$. Además, se establece expresamente que cuando "el responsable haya hecho públicos los datos personales, éste está obligado a adoptar las medidas razonables -incluidas las técnicas- en lo que respecta a los datos de cuya publicación sea responsable con miras a informar a los terceros que están tratando dichos datos de que un interesado les solicita que supriman cualquier enlace a estos datos personales, o cualquier copia o réplica de los mismos. Además, cuando el responsable del tratamiento haya autorizado

11 Se destaca que la posición jurídica de los ciudadanos frente a las grandes corporaciones internacionales que llevan a cabo tratamientos de datos personales a través de redes sociales virtuales, motores de búsqueda o servicios de computación en nube ha mejorado considerablemente al contemplar la propuesta de Reglamento expresamente el sometimiento a este de las entidades no establecidas en la Unión Europea que traten datos de residentes en la Unión para ofrecerles bienes o servicios o para controlar su conducta (art. 3.3); además, los responsables del tratamiento no establecidos en la Unión tienen que designar un representante en la misma (art. 25). A esto se suma que los proveedores de servicios de Internet y los buscadores tienen la obligación de limitar la recogida de datos al mínimo necesario (art. 5.c), y deberán informar a los usuarios de forma transparente sobre quién recoge y usa sus datos y sobre cómo, con qué fines y por cuánto tiempo lo hace (arts. 14 y 15). 
a un tercero a publicar datos personales, será considerado responsable de la publicación" (art. 17.2). De esta forma, cuando los datos personales se hayan hecho públicos, sobre todo en Internet, el responsable deberá velar por la cancelación de los mismos de cualquier link, copia o réplica de los mismos que se encuentre accesible en servicios de comunicación que faciliten su búsqueda.

El principal problema que plantea la publicación en Internet está en los efectos multiplicadores que realizan los buscadores, por ejemplo, Google o Yahoo, que permiten localizar información relacionada con personas. La Comisión consciente de la existencia de este problema, lo ha resuelto de la mejor manera posible -0 , a nuestro juicio, de la única manera razonable-. Frente a quienes han mantenido que el derecho al olvido en Internet debía pivotar sobre el derecho de oposición ejercido sobre los motores de búsqueda como responsables de sus propios tratamientos -esta sería la posición de la AEPD en las Resoluciones de tutela de derechos frente a Google-, la propuesta de Reglamento construye el derecho al olvido en Internet sobre las obligaciones del responsable principal -de la web máster- que ha hecho público los datos ${ }^{12}$. Por ello, la regulación del derecho al olvido que hace la propuesta de Reglamento establece una obligación del responsable de la publicación de

12 Esta es la posición que hemos mantenido desde el año 2008 en nuestros trabajos "Transparencia administrativa y protección de datos personales", en Transparencia administrativa y protección de datos personales, Civitas-APDCM, Madrid, 2008, pp. 23-188, esp. pp. 101112 y, recientemente, en La protección de datos personales. En busca del equilibro, Tirant lo Blanch, Valencia, 2010, pp. 816-831. Lógicamente, la Comisión está a la espera de que el Tribunal de Justicia resuelva la cuestión prejudicial planteada por la Audiencia Nacional en relación con las Resoluciones de tutela de derechos frente a Google. los datos en Internet, no solo de suprimir los datos personales sino de comunicar a terceros que están tratando dichos datos que el interesado solicita que se suprima cualquier enlace, copia o réplica de los mismos, relacionando una cosa con la otra, y exigiendo al responsable de la primera publicación que adopte "todas las medidas razonables, incluidas las técnicas", lo que, a nuestro juicio, le obliga a implantar mecanismos que impidan la indexación -aunque esta obligación de implementar tecnología que impida la difusión generalizada debería aparecer con más claridad en la propuesta de Reglamento-. De esta forma, tiene en cuenta las diferentes responsabilidades de la Administración y de los buscadores en relación con la publicación de boletines oficiales y páginas web institucionales en abierto de Internet. A nuestro juicio, el responsable del tratamiento es el órgano administrativo que ordena la publicación de la información y que tiene la competencia administrativa sobre la materia a la que se refiere la publicación de los datos personales. Es este órgano administrativo que aprueba la disposición o el acto y que ordena la publicación el que determina los datos personales que van a ser objeto de tratamiento -datos de concursantes, datos de excluidos, datos de minusvalía, DNI, etc.-, el tipo de publicidad -el diario oficial, Internet, espacio privado en Internet, Intranet- y el plazo de publicación -que debe terminar cuando se haya cumplido la finalidad-. Es este órgano el que puede informar al interesado de la finalidad de la publicación y de la disposición legal que la habilita. También, debe dar respuesta al interesado que ejercita los derechos de acceso, rectificación, cancelación y oposición, y el que debe 
determinar la obligación de bloqueo de los datos publicados en un diario oficial, la limitación de la accesibilidad a los motores de búsqueda o la supresión de la publicación en Internet cuando el tratamiento ya no sea necesario, dando las instrucciones precisas al responsable del boletín oficial o de la web institucional. La garantía del "derecho al olvido", cuando la publicación de la información contiene tratamientos excesivos o ya no es necesaria para la finalidad y se ha cumplido el plazo que la justificaba pasa porque el responsable de la publicación se abstenga de darle más difusión, dejando de publicar la información o, al menos, implante las soluciones técnicas que limiten la facilidad de búsqueda (findability/searchability) de la información -en este caso, administrativa- que contenga datos personales $^{13}$. De hecho, la propuesta de Reglamento obliga al responsable del tratamiento a

13 Que pasados los años cada vez que una persona ponga su nombre en un buscador en Internet aparezca que fue indultada por un delito, que no pagó una multa o fue perceptora de una renta mínima de inserción social es muy gravoso para esa persona y no hay aparentemente un interés público que lo justifique. Lógicamente, la implantación de este sistema de referencias negativas que impidan la localización y tratamiento de datos personales recogidos en boletines oficiales y en sitios webs en Internet a través de motores de búsqueda exige diferenciar qué información del boletín oficial o de la web debe permitir o no la indexación de su contenido, lo que conlleva también una modificación tecnológica. El documento del Grupo de Trabajo del Artículo 29 recomienda aprovechar las herramientas que facilitan los mismos buscadores con el fin de evitar que la información se guarde en la memoria temporal de estos. A dichos efectos, es conveniente que los sitios webs utilicen herramientas técnicas e informáticas del tipo "NO ROBOT" que minimicen, en la medida de lo posible, la diseminación de la información de carácter personal, a la que se pueda acceder a través de los motores de búsqueda. Hay que señalar que existe un acuerdo de los principales buscadores que obliga a respetar las instrucciones sobre indexación que se incluyan en el fichero robots. txt que se inserta dentro del código "html" de las páginas web. No se trata de una norma jurídica, sino de un acuerdo entre compañías que los buscadores principales respetan. A través del fichero robots. txt se pueden dar instrucciones para que no se indexe nada de un sitio web, de un directorio, de directorios concretos e incluso de ficheros específicos. Otro mecanismo disponible para limitar la indexación y que funciona a nivel de página web -por lo que no se puede aplicar a partes de una página web- son los TAGS META, a través de los que se puede indicar que una página web se indexe o no o bien que se impida o se permita el escaneo de los enlaces que aparecen en la misma. implementar mecanismos para garantizar que se respetan los plazos fijados para la supresión de datos personales y/o para el examen periódico de la necesidad de conservar los datos (art. 17.7). Además, establece que el responsable está obligado a limitar el tratamiento cuando ya no necesite los datos para la realización de su misión, pero estos deban conservarse a efectos probatorios (art. 17.4) ${ }^{14}$. Se especifican, asimismo, los límites a la supresión cuando exista un deber legal de conservar los datos personales por motivos de interés público, pero obligando a respetar siempre el principio de proporcionalidad (art. 17.3.d), lo que requiere, a nuestro juicio, a limitar los tratamientos excesivos. Le faltaría a la propuesta de Reglamento especificar que esta limitación del tratamiento en el marco del derecho al olvido es una limitación de la publicidad (Guichot, 2010) ${ }^{15}$.

14 La propuesta de Reglamento también establece que cuando el interesado impugne la exactitud de los datos personales, el responsable está obligado a limitar el tratamiento de datos, durante el plazo que le permita verificar la exactitud de los mismos (art. 17.4).

15 La defensa de la limitación de los tratamientos -en especial de la publicidad- cuando esta no sea necesaria para la finalidad la hemos defendido en el apartado "La prohibición de tratamientos excesivos, la cancelación de la publicación, la integridad e inalterabilidad de los boletines oficiales y la problemática de los buscadores", (Guichot, 2008, pp. 67-75). Lógicamente como hemos señalado, "Ios límites a la buscabilidad no deben extenderse a la totalidad de la publicación del número del boletín -para lo que obviamente no tiene competencia el responsable que aprobó la resolución-, ni siquiera a la totalidad de la resolución -la parte dispositiva debe continuar siendo objeto de publicación-, sino únicamente a aquella parte que suponga un tratamiento de datos personales que sea considerado excesivo al haberse cumplido ya la finalidad que lo justificó. Esta limitación al tratamiento se refiere lógicamente a los datos personales publicados en la edición electrónica del boletín oficial y no, lógicamente, ni a la edición en papel -que no constituye un tratamiento de datos- ni a los datos personales incluidos en el procedimiento administrativo cuya resolución dio lugar a la publicación. Esto obliga a modificar la forma de publicación de la versión electrónica del boletín oficial, lo que conlleva una adaptación tecnológica. Por ello, el criterio de publicación del boletín oficial en Internet no puede ser el de hacerlo en un solo documento -Word o pdf-. Tiene que hacerse por partes y de manera dinámica, de forma que permita el bloqueo separado de la información, ya que un mismo número de boletín contendrá resoluciones con distintos plazos y fechas de caducidad -y lo mismo ocurre dentro de la misma resolu- 
Los buscadores se encuentran en una situación jurídica radicalmente distinta. Estos buscadores revisan las páginas de Internet cada cierto tiempo para indexar su contenido y actualizarlo si se han producido cambios, llevando a cabo un tratamiento en la memoria caché y almacenando una colección de información - un diccionario- que facilita y agiliza las búsquedas. Está claro que el buscador es responsable de este tratamiento, especialmente cuando esta información ha desaparecido de la fuente inicial. Así, tienen que respetar el principio de calidad (art. 4 LOPD), que obliga a que los tratamientos sean exactos y puestos al día, de forma que respondan con veracidad a la situación actual del afectado, y aquellos que sean inexactos o incompletos deben ser cancelados y sustituidos de oficio, debiendo cancelar la información cuando haya dejado de ser necesaria o pertinente. Por tanto, los responsables de los motores de búsqueda deben adecuar los sistemas de recopilación de referencias, los índices y las estaciones de almacenamiento temporal, de manera que respondan al contenido actual. Es responsabilidad de los buscadores anonimizar las búsquedas pasados los seis meses y borrar las cookies. Además, los buscadores deben garantizar el ejercicio de los derechos de acceso, rectificación, cancelación y oposición sobre sus propios tratamientos ${ }^{16}$. La propuesta de Reglamento re-

ción-. En definitiva, se trataría de dejar de publicar los "documentos electrónicos" como un todo a publicarlos como un "puzzle" -ya que habría que considerar en cada información el plazo de bloqueo-. Naturalmente, este planteamiento supone una modificación técnica de las plataformas que dan soporte a la publicación de los boletines oficiales, que tiene un coste tanto en términos económicos como en plazo de implantación".

16 Cfr. el Informe del Grupo de Trabajo del Artículo 29, de 4 de abril de 2008, que analizó la protección de datos personales en relación con los buscadores de Internet. conoce al interesado el derecho a oponerse en cualquier momento, por motivos relacionados con su situación particular (el art. 6.2 LOPD precisaba aún más señalando "motivos fundados y legítimos relativos a una concreta situación personal") a que sus datos personales sean objeto de un tratamiento que se ha basado en la necesidad de proteger sus intereses vitales, en el cumplimiento de una misión de interés público o inherente al ejercicio del poder público o en la satisfacción de un interés legítimo perseguido por el responsable o por el cesionario, siempre que no prevalezca el interés o los derechos y libertades del interesado (arts. 19 y 6$)^{17}$. El ejer-

17 Los motores de búsqueda tratan habitualmente datos procedentes de fuentes accesibles al público, lo que les permite acogerse a las excepciones al consentimiento y a la cesión establecidas en los arts. 6.2 y 11.2.b LOPD, sin perjuicio de tener que respetar legalmente el derecho de oposición en virtud del art. 6.2 LOPD -con las dificultades que después señalaremos-. Lógicamente, el hecho de que la calificación como fuente accesible al público suponga unas excepciones al derecho a la protección de datos personales $-y$, por tanto, un límite a un derecho fundamental- requiere que se lleve a cabo una interpretación restrictiva de los tratamientos de datos personales que tienen esta consideración, salvo que se ejerza otro derecho fundamental-como sería la libertad de información y que influye en la delimitación de qué se entiende por medio de comunicación social-. Por tanto, las fuentes accesibles al público en virtud del art. 3,j de la LOPD y del art. 7 del RPDP tienen un carácter tasado, y entre estas no se incluyen las páginas web publicadas en Internet -salvo, de nuevo, que se ejerza la libertad de información y puedan ser consideradas medios de comunicación social-. Esto obliga también a los buscadores a respetar los principios de finalidad y de consentimiento en los tratamientos de datos personales que se encuentren en páginas de Internet, lo que no siempre es posible. La AEPD ha insistido en el carácter taxativo de la calificación de fuentes accesibles al público en la LOPD, "lo que impide que consideremos a las páginas web como fuentes accesibles al público. Por ello, para tratar la información contenida en dichas páginas debería de obtenerse el consentimiento de los afectados. Por otro lado, para poder utilizar la información contenida en las mismas debe justificarse la finalidad, principio esencial en materia de protección de datos que se contempla en el artículo 4 de la Ley Orgánica". Cfr. Informe 0342/2008 del Gabinete Jurídico de la AEPD: "Recabar datos de páginas web, no constituye un tratamiento basado en fuentes accesibles al público", en http://www.agpd.es/portalwebAGPD/canaldocumentacion/ informes juridicos/conceptos. También, la Audiencia Nacional ha mantenido una interpretación restrictiva del concepto de "fuentes accesibles al público". Así, la Sentencia, de 18 de febrero de 2007 señala: "Del tenor literal de dicho precepto, se desprende con claridad que recoge un número clausus o enumeración cerrada de las Fuentes que pueden calificarse como accesibles al público, lo que se remarca con el empleo del término "exclusivamente" que se anuda a las concretas fuentes que enumera. Criterio este que es el seguido por la Sala entre 
cicio de este derecho obliga al responsable a dejar de usar o a tratar de cualquier forma los datos personales ${ }^{18}$. El derecho al olvido y a la supresión obliga al responsable del tratamiento a suprimir los datos personales y a abstenerse de darles más difusión cuando el interesado se oponga al tratamiento de datos personales (art. 17.1c)- ${ }^{19}$. Sin embargo, no es razonable ni posi-

otras en las SSAN, Sec $1^{\text {a }}$, de 18-5-2006 (Rec.35/2005), 17 de marzo 2006 (Rec. 62/2004), 18-1-2007 (Rec. 240/2005), 24 de abril de 2007 (Rec. 304/05) etc, añadiendo en la última de las sentencias citadas, que en el inciso segundo de dicho precepto debe ser interpretado en relación con el primero" Cfr. Lesmes (2008, pp. 124-133), De la Serna Bilbao, (2010, pp. 256-295). La STJUE, de 6.11.2003, As. Lindqvist recuerda que las páginas de Internet que incluyan datos de personas identificadas o identificables constituyen tratamientos de datos personales: "la conducta que consiste en hacer referencia, en una página web, a diversas personas y en identificarlas por su nombre o por otros medios, como su número de teléfono o información relativa a sus condiciones de trabajo y a sus aficiones, constituye un tratamiento total o parcialmente de datos personales", por lo que está dentro del ámbito de aplicación de la Directiva 95/46/CE.

AEPD ha reconocido el derecho de oposición de un ciudadano frente al tratamiento que Google ha hecho de sus datos publicados en un boletín oficial de la Diputación -R 1046/2007, de 20 de noviembreGoogle alegaba que "la solución dependía del bloqueo de la página de donde salen los resultados, por el titular de la web referenciada", es decir, el boletín oficial de la Diputación. Entendia que las informaciones obtenidas a través de sus resultados de búsqueda se encuentran en páginas de terceros que son fuentes accesibles al público, por lo que para eliminar dicho contenido debería desaparecer también de la web máster de la página de terceros. Google señala que "aunque pudiéramos eliminar la página ofensiva de nuestro índice, ésta seguiría apareciendo en la red. Cada pocas semanas nuestros robots rastrean la web [...] si el sitio está disponible en Internet [...] será añadido a nuestro índice si el sitio está disponible en Internet". La AEPD mantenía que las personas tienen un derecho de oposición para evitar la difusión pública que de sus datos personales hacen los buscadores a partir de fuentes de acceso público y que genera un efecto negativo permanente en contra de la voluntad de los afectados. La actividad de Google cuando indexa información de diarios oficiales no se encuentra amparada por la libertad de expresión y no hay una disposición legal que limite el ejercicio del derecho de oposición frente a los buscadores. Además, señalaba que Google tiene la obligación de contestar expresamente a la solicitud de ejercicio del derecho de oposición. Por lo que la AEPD concluye que "procede la exclusión de los datos personales del reclamante de los índices elaborados por Google, por lo que se estima el presente procedimiento de tutela de derechos". Sin embargo, a nuestro juicio, la problemática principal -la lesión del derecho fundamental- proviene en este supuesto del tratamiento excesivo de datos personales derivado de la publicación en un diario oficial de una resolución sancionadora por infracción de la ordenanza municipal de convivencia ciudadana que prohíbe orinar en la vía pública por lo que parece, que ante una previsible desatención por parte de la Cor- ble centrar el derecho al olvido en Internet como una obligación que descansa principalmente en la responsabilidad de los motores de búsqueda, olvidando otras responsabilidades mucho más graves en las que incurre el responsable de la publicación inicial y haciendo caso omiso de las propias características de los tratamientos que Ilevan a cabo los motores de búsqueda - de carácter únicamente técnico-. La LOPD permite ejercer el derecho de oposición frente a los tratamientos que procedan de fuentes accesibles al público (art. 6.2), un planteamiento adecuado para otra etapa tecnológica caracterizado por el uso que determinadas empresas de marketing o de solvencia patrimonial hacían de algunas fuentes accesibles al público como los repertorios telefónicos, las listas de personas pertenecientes a grupos profesionales o diarios oficiales, pero que no es igualmente trasladable a un supuesto de hecho completamente distinto: Ios enlaces, copias o réplicas de web másters que se producen en Internet. El ejercicio del derecho de oposición ante los responsables de los motores de búsqueda que llevan a cabo millones de enlaces a webs cada hora -y donde trabajan muy pocas personas- no puede ser el procedimiento principal para resolver el problema de los tratamientos de datos excesivos, que es, en el fondo, el problema del derecho al olvido en Internet cuando el responsable principal es, por ejemplo, una Administración Pública, un medio de comunicación -como se verá más adelante- o una web institucional conocida que han adoptado la decisión - no tecnológica- que ha

poración internacional radicada en EEUU, lo más adecuado primero es exigir el cumplimiento del principio de calidad a la Administración Pública que está cercana. 
conllevado una publicación de datos excesivos. No parece que el derecho al olvido en Internet de los afectados por las innumerables publicaciones de datos personales excesivas en diarios oficiales - de una sanción por orinar en la vía pública, de una situación de incapacidad permanente, de ser titular de una ayuda a la pobreza- vaya a ser resuelta a través del ejercicio del derecho de oposición ante el motor de búsqueda, que tendría que atender las innumerables reclamaciones de los afectados y cancelar las búsquedas de millones de personas potenciales. Tampoco, los motores de búsqueda pueden diferenciar fácilmente entre webs institucionales donde hay que respetar el principio de finalidad y de consentimiento, y diarios oficiales que son fuentes accesibles al público, cuando todos ellos están publicados igualmente en Internet. Asimismo, no es fácil para el buscador diferenciar las solicitudes de oposición y cancelación relativas a tratamientos que provienen de publicaciones en diarios oficiales, que lleva a cabo una Administración Pública sin ejercer un derecho fundamental, de aquellas otras que provienen de webs que manejando fuentes administrativas llevan a cabo una crítica política, que puede suponer un tratamiento de datos personales con fines periodísticos o de aquellas web másters que suponen tratamientos de datos personales con fines de expresión literaria o artística, donde, como se señala más adelante, no se puede limitar la indexación por los motores de búsqueda como garantía de la libertad de expresión. Como se ha dicho, la decisión el responsable del tratamiento de publicar en abierto en Internet, pudiéndolo hacer en un espacio privado en Internet o en una Intranet y la negativa de instrumentar mecanismos de no indexación le convierte en el responsable de la publicación y de los tratamientos posteriores. Por ello, parece que lo razonable es que la responsabilidad principal de garantizar el derecho al olvido recaiga en el responsable también principal que ha hecho públicos los datos. Lógicamente, la responsabilidad del buscador sí se extiende a algunos supuestos específicos: cuando la web máster está en un paraíso fiscal, no responde o ha desaparecido; cuando el buscador se niegue a borrar la información habiéndoselo comunicado el responsable principal; cuando los tratamientos de datos personales supongan actividades delictivas o que vulneran gravemente los derechos; situaciones concretas que sí pueden ser gestionados por los responsables de los motores de búsqueda a través de sus propios canales de denuncia como herramienta de autorregulación -que funcionan adecuadamente, como en el caso de Youtube, que se verá más adelante- ante la solicitud de los propios perjudicados, requerimientos de las autoridades de control o medidas cautelares solicitadas por Ios jueces. En todo caso, a la propuesta de Reglamento le falta contener una referencia explícita a la facultad del interesado de dirigirse al responsable de los tratamientos relativos a enlaces, copias o réplicas de otros tratamientos principales en estos supuestos.

Pues bien, esta posición es la que -afortunadamente- adopta la propuesta de Reglamento, que, al regular los tratamientos de datos personales que consisten en enlaces, copias o réplicas de los tratamientos principales, los excluye del derecho de oposición, al establecer que el 
derecho al olvido o a la supresión se materializa a través de un procedimiento específico ante el responsable que publicó inicialmente los datos (art. 17.2). Así, se establece que le corresponde al responsable del tratamiento que ha hecho públicos los datos informar a los terceros que están tratando dichos datos que el interesado les solicita que supriman cualquier enlace a sus datos personales o cualquier copia o réplica de los mismos. Además, como se ha señalado antes, no le basta al responsable con informar a los terceros, sino que tiene que adoptar las medidas técnicas que impidan cualquier enlace, copia o réplica de los mismos. El derecho al olvido no se garantiza con un procedimiento en el que el interesado se dirige y le exige al buscador que cancele la información sino que tiene que ejercitar su derecho ante el responsable que publicó inicialmente los datos personales, quedando obligado este responsable a comunicar al tercero que trata los datos, "que el interesado les solicita que supriman cualquier enlace a estos datos personales, o cualquier copia o réplica de los mismos". El que atiende la solicitud de derecho al olvido es, por tanto, el responsable de la publicación inicial, no el buscador, y le corresponde al primero trasladar la petición al segundo, debiendo cancelar ambos. De hecho, el responsable de la publicación inicial no solo deber informar a terceros sino también adoptar todas las medidas razonables, incluso las técnicas, para comunicar esta información. Pero, aun va más allá la propuesta de Reglamento: ante quien pretenda seguir interpretando que los motores de búsqueda tienen el carácter de responsables de sus propios tratamientos -ya que en el ámbito de la protección de datos solo se pue- den tratar los datos en calidad de responsable o de encargado y, obviamente, los motores de búsqueda no son encargados del tratamiento de la web máster principal-, y, que, por tanto, se encuentran obligados a suprimir los datos y abstenerse de darles más difusión (ex art 17.1), la propuesta de Reglamento es taxativa en cortar esa línea interpretativa: "cuando el responsable del tratamiento haya autorizado a un tercero a publicar datos personales, será considerado responsable del tratamiento". Es decir, que el responsable del tratamiento de los links, copias o réplicas sigue siendo el responsable principal que publicó los datos. De esta forma, solo puede actuarse frente al motor de búsqueda cuando este no siga las instrucciones del responsable. Es decir, la propuesta de Reglamento hace desaparecer el derecho de oposición frente al motor de búsqueda cuando se mantiene la publicación en la fuente principal.

Así, ha planteado problemas en España la determinación de cuál era el grado de responsabilidad del buscador cuando la información administrativa sigue siendo publicada en la fuente original -en el boletín o diario oficial o en la web de la Administración-. Era necesario precisar en qué medida se puede exigir una responsabilidad al buscador por encontrar una información que la Administración mantiene publicada y que se niega a cancelar en la página de Internet, a bloquear en el boletín o diario oficial o a limitar la posibilidad de indexación. Como se ha defendido en el pasado reiteradamente, existen en este caso dos responsables de tratamiento: el de la página principal -que sería la Administración- y el buscador. Parece que la responsabilidad prin- 
cipal la tendría la Administración que mantiene la publicación en Internet. No es razonable exonerar de responsabilidad a la Administración, en virtud de la existencia de una habilitación legal o de la propia naturaleza de los boletines oficiales para atribuírsela en exclusiva y únicamente al buscador, olvidando que los primeros están también obligados a respetar el principio de calidad y de proporcionalidad ${ }^{20}$. Así las cosas, la Administración, que elige indebidamente el medio de publicación - publicando en el boletín oficial lo que podría estar en un espacio privado en Internet-, publica datos excesivos y se niega a ordenar que el boletín oficial o la web institucional realice los cambios organizativos necesarios para evitar los tratamientos excesivos es responsable de las infracciones en este ámbito y no puede diluir su responsabilidad en Google - por poner un ejemplo-, que se limita a buscar la información que la Administración mantiene publicada. No es razonable que la Administración Pública se niegue a implementar unos mecanismos sencillos ofrecidos por los propios buscadores para evitar la indexación de los contenidos y, al mismo tiempo, se atribuya única-

20 El problema principal de que alguien que ha orinado en la vía pública o que ha recibido una ayuda a la pobreza aparezca publicado en un diario oficial lo ocasiona -valga la redundancia- quien lo ha publicado, no el buscador, y es, por tanto, el primero de ellos el que tiene que resolver el problema. De hecho, es mucho más rentable y eficaz para el ciudadano que la autoridad de control se centre en la Administración Pública que tiene muy cerca -por no decir al lado- a que se dirija al buscador que está afincado en EEUU. Pero, también es verdad que para la autoridad de control es más valioso, en términos de aparición en los medios de comunicación, un litigio con una corporación internacional que con una Administración Pública. Esto último supone un desgaste a nivel político muy elevado. En general, en muchas ocasiones, es más cómodo para una autoridad de control atribuirle la responsabilidad a una entidad privada que dirigirse contra la Administración -Ministerios, Consejerías o Direcciones Generales-. Esto le ocurre especialmente a las Agencias autonómicas en su relación con las Administraciones Autonómicas y con las Administraciones Locales donde se dan la mayoría de las publicaciones excesivas. Los buscadores no pueden estar a resolver los problemas de lo que hacen mal las Administraciones Públicas. mente la responsabilidad de la publicación a los buscadores. Además, téngase en cuenta que los boletines oficiales tienen en virtud de una Ley el carácter de fuente accesible al público, lo que permite que su consulta pueda ser realizada por cualquier persona, no impedida por una norma limitativa o sin más exigencia que, en su caso, el abono de una contraprestación (art. 3 LOPD) y que su tratamiento y su cesión inicial pueden hacerse sin consentimiento del interesado (arts. 6.2 y 13.2.b LOPD). Por tanto, el planteamiento de este análisis se encuentra más centrado en controlar a las Administraciones Públicas y someterlas al principio de calidad, que es el centro del problema. Además, existe en este punto una legislación de protección de datos personales y unos tratamientos de datos personales que caen inexcusablemente dentro del ámbito de control de las Agencias de Protección de Datos, sin necesidad de dirigirse a corporaciones internacionales que tienen su sede fuera de la Unión Europea. Todo ello sin perjuicio de exigir en su caso alguna responsabilidad a los buscadores por los tratamientos en la memoria caché en los supuestos concretos antes mencionados. Pero, no parece razonable eximir de responsabilidad a la Administración y obligar a los buscadores a no encontrar la información que esta mantiene publicada en un diario oficial. Aunque los buscadores eliminaran la página del índice, seguiría siendo buscada en Internet por otros buscadores y en pocas semanas los robots volverían a rastrear si el sitio está disponible en Internet y añadirlo al índice. Así, el ciudadano que se encuentre con tratamientos de sus datos personales excesivos debe ejercer su derecho de cancelación ante el responsable 
del tratamiento principal, que es la Administración que mantiene publicada la información personal, no el buscador ${ }^{21}$. La responsabilidad

21 Sin embargo, la Resolución 463/2007 de la Agencia Española exime de cualquier responsabilidad al Boletín Oficial de la Provincia de Barcelona y reconoce un derecho de oposición frente a Google. Señala esta Resolución que la Ley "no dispone que los datos personales del reclamante figuren en los índices que utiliza Google para facilitar al usuario el acceso a determinadas páginas, ni tampoco dispone que figuren en las páginas que Google conserva temporalmente en memoria cache". Sin embargo, Google busca y trata una información del Boletín Oficial de la Provincia de Barcelona que es una fuente accesible al público. Cfr. también las Resoluciones de la AEPD R/01046/2007, de 20 de noviembre, R/00303/2007, de 25 de mayo, y R/00598/2007, de 27 de julio, que obligaban a Google a dejar de indexar el nombre de una persona que aparecía en una sanción administrativa publicada en el Boletín Oficial de la Provincia. Igualmente, la Resolución 266/2007 de la Agencia Española señala que "ningún ciudadano que ni goce de la condición de personaje público ni sea objeto de hecho noticiable de relevancia pública tiene que resignarse a soportar que sus datos de carácter personal circulen por la red sin poder reaccionar ni corregir la inclusión ilegítima de los mismos en un sistema de comunicación universal como Internet [...] Resulta palmariamente legítimo que el ciudadano que no esté obligado a someterse a la disciplina del ejercicio de las referidas libertades -de expresión e información- (por no resultar sus datos personales de interés público ni contribuir, en consecuencia, su conocimiento a forjar una opinión pública libre como pilar básico del Estado democrático) debe gozar de mecanismos reactivos amparados en Derecho (como el derecho de cancelación de datos de carácter personal) que impidan el mantenimiento secular y universal en la Red de su información de carácter personal. Pero, la solución es dirigirse al responsable del tratamiento y no al buscador. La Audiencia Nacional ha dictado un auto en el que plantea una cuestión prejudicial al TJUE -Auto de la Sala de lo Contencioso-Administrativo de la Audiencia Nacional, de 27 de febrero de 2012-. Cfr. supra apdo. V.A). Cfr. recientemente el interesante trabajo de Castellano (2012, pp. 135-212). Nuestro planteamiento de exigir las responsabilidades principalmente a la Administración y no al buscador se materializó tempranamente en la APDCM, a través de la Resolución del 13 de febrero de 2007, una tutela de derechos que reconoce el derecho a la cancelación-que en este caso equivaldría al bloqueo- en la edición digital del Boletín Oficial de la Comunidad de Madrid de la información de haber sido adjudicatario de una prestación económica de renta mínima de inserción social que se había publicado para cumplir la normativa de notificación de los actos administrativos establecida en el art. 59 de la Ley 30/1992, de 26 de noviembre. En esta resolución se exigió a la Dirección General de Servicios Sociales que ordenase al Boletín Oficial de la Comunidad de Madrid la cancelación -el bloqueo- de la publicación en la edición electrónica al considerar que el mantenimiento de esa publicidad en Internet, cumplida ya la finalidad de la notificación, era un tratamiento excesivo que no respetaba el principio de calidad, además que dicha publicación contenía datos excesivos. Así, en los procedimientos de subvenciones o de ayudas sociales -para personas con discapacidad, víctimas de violencia de género- donde la información afecta a la intimidad y puede lesionar derechos y donde el interés público es menor, la publicación debe limitarse a una somera indicación del contenido del acto y del lugar donde los interesados pueden comparecer dentro del plazo correspondiente para tener acceso íntegro. Lo mismo debería hacerse cuando la publicación de datos personales se produce por problemas de notificación -por ejemplo, de resoluciones sancionadoras de la Administración-. Cfr. especialmente la Recomendación por la infracción de no cancelar la información debe atribuirse principalmente a la Administración, no al buscador. Exigir la cancelación a los buscadores no parece lo más práctico cuando existen un número amplísimo de estos -y muchos más que pueden crearse en el futuro-. Es importante entender que en Internet todo se replica por distintos mecanismos. No solo son los buscadores conocidos los que utilizan robots de búsqueda, sino que también los emplean los medios de comunicación, las empresas de multas, las editoriales jurídicas, etc., que disponen de sus propios robots programados de acuerdo con sus necesidades. Además, muchos de los buscadores se encuentran fuera de España consecuencia lógica de la universalidad de Internet- y hasta ahora ha sido muy difícil garantizar la aplicación de la Directiva y de la ley española y la ejecución de las resoluciones de las autoridades de protección de datos de España. Quiero que se me entienda bien: existe también una responsabilidad secundaria del buscador, pero, en los temas que están a debate la responsabilidad principal la tiene la fuente original que es la Administración Pública, que ha publicado reiteradamente en un diario oficial o en Internet datos excesivos -incluso especialmente protegidos- para la finalidad y que los mantiene publicados pese a que se haya cumplido esta, negándose a adoptar ningún mecanismo técnico que impida la indexación; en cambio, los

\footnotetext{
2/2008, de 25 de abril, de la APDCM, sobre publicación de datos personales en boletines y diarios oficiales en Internet, en sitios webs institucionales y en otros medios electrónicos y telemáticos -llama la atención que la AEPD no haya aprobado todavía un texto semejante y siga centrando sus Resoluciones únicamente en los buscadores-. La explicación doctrinal de los criterios que permiten la actividad de ponderación entre la transparencia y la protección de datos personales y su aplicación a supuestos conflictivos la hemos hecho en (Troncoso, 2008, pp. 61-165), (Troncoso, 2010, cit. pp. 760-904).
}

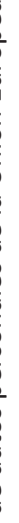


buscadores son básicamente herramientas técnicas, y que tienen sin duda una responsabilidad, pero que no es, en absoluto, la principal ${ }^{22}$.

La propuesta de Reglamento cierra el debate sobre la determinación de la responsabilidad de los diferentes actores - de quien publica inicialmente la información en Internet y de los motores de búsqueda que llevan a cabo los tratamientos posteriores- y ante quien deben ejercitarse los derechos. Así, la propuesta de Reglamento centra el derecho al olvido en Internet en que "el responsable de la publicación inicial suprima los datos y se abstenga de darles más difusión" (art. 17.1); obliga al responsable que haya hecho públicos los datos no solo a suprimir la publicación sino también a dirigirse a los terceros que estén tratando dichos datos para informarles de que un interesado les solicita que supriman cualquier enlace a estos datos personales o cualquier copia o réplica de los mismos (art. 17.2); obliga al responsable a adoptar medidas técnicas para que los terceros supriman cualquier enlace, copia o réplica de los mismos, lo que le obliga a establecer límites

22 Hay un debate de fondo sobre la responsabilidad de las herramientas. Esto ha surgido también cuando la industria de los contenidos ha pedido responsabilidad civil a los programadores que han diseñado sistemas de compartir archivos mediante redes descentralizadas en las que miles de internautas son al mismo tiempo clientes y servidores, creando una comuna informática anónima -programas $\mathrm{P} 2 \mathrm{P}$ como eMule o Piolet-. La tecnología es siempre neutral. En todo caso, los buscadores deberían tratar de implementar aquellos mecanismos de privacidad por defecto que sean técnicamente posibles, aplicando una fórmula semejante a la que pueden emplear las empresas de publicidad o prospección comercial cuando emplean fuentes accesibles al público -Guía de Telecomunicaciones, listados profesionales-, en las que los interesados le han manifestado su derecho de oposición al tratamiento aunque todavía no ha podido ser hecho efectivo en la fuente accesible al público hasta la publicación de la siguiente edición. Los buscadores podrían valorar la posibilidad de manejar listados de excluidos - para facilitar el funcionamiento de los canales de denuncia en los supuestos ya señalados-, sin perjuicio de las obligaciones del responsable principal que ordena y mantiene la publicación de la información. a la indexación (art. 17.2); señala que cuando el responsable del tratamiento haya autorizado a un tercero a publicar datos personales - lo ha autorizado cuando publica la información en un boletín oficial que tiene el carácter de fuente accesible al público o se niega a establecer herramientas que impida la indexación - será considerado responsable de la publicación (art. 17.2 in fine); obliga al responsable del tratamiento a implementar mecanismos para garantizar que se respetan los plazos fijados para la supresión de datos personales y/o para el examen periódico de la necesidad de conservar los datos (art. $17.7)^{23}$.

\section{LOS LÍMITES AL DERECHO AL OLVIDO: LA PUBLICACIÓN DE LOS ME- DIOS DE COMUNICACIÓN EN INTER- NET Y EL EJERCICIO DE LA LIBERTAD DE EXPRESIÓN}

El derecho a la protección de los datos personales, como el resto de los derechos reconocidos en la Carta de los Derechos Fundamentales de la Unión Europea, no es un derecho absoluto sino que se encuentra sometido a límites. Así,

23 La propuesta del Reglamento insiste en la importancia de suprimir los datos cuando ya no sean necesarios en relación con los fines y se haya cumplido el periodo de almacenamiento (art. 17.1), algo especialmente aplicable a la publicación de datos personales por las Administraciones Públicas. Así, establece que el límite al derecho de supresión derivado del cumplimiento de una obligación legal de conservar los datos personales, como puede ser la existencia de unos diarios oficiales, debe respetar el principio de proporcionalidad (art. 17.3.d). Incluso, regula la posibilidad de limitar el tratamiento de datos personales cuando ya no sean necesarios para la realización de su misión pero éstos deban conservarse a efectos probatorios (art. 17.4.b). Este trabajo se centra en exponer las principales novedades del Reglamento. La prohibición de tratamientos excesivos, la cancelación de la publicación y la integridad e inalterabilidad de los diarios oficiales se puede encontrar en Troncoso, La protección de datos personales. En busca del equilibrio, 2010. cit. pp. 760-904. 
el art. 52.1 de la Carta, relativo al "Alcance e Interpretación de los derechos y principios", señala que "cualquier limitación del ejercicio de los derechos y libertades reconocidos por la presente Carta deberá ser establecida por Ley y respetar el contenido esencial de dichos derechos y libertades. Dentro del respeto del principio de proporcionalidad, sólo podrán introducirse limitaciones cuando sean necesarias y respondan efectivamente a objetivos de interés general reconocidos por la Unión o la necesidad de protección de los derechos y libertades de los demás" 24 . En esta dirección, la propuesta de Reglamento recoge expresamente que la protección de los derechos y libertades de otras personas es otra finalidad legítima que permite establecer límites a los principios y derechos de protección de datos (art. 21.1.f). El derecho a la protección de datos personales, como ha señalado el TJUE, "no es un derecho absoluto sino que debe considerarse en relación con su función en la sociedad y mantener el equilibrio con otros derechos fundamentales, con arreglo al principio de proporcionalidad" 25 .

24 Cfr. Mangas (2008, pp. 826-851). A diferencia del CEDH, que establece expresamente en el mismo art. 8 que reconoce el derecho a tener vida privada cuáles son sus límites, la Carta proclama de manera absoluta el derecho a la protección de datos en el art. 8, estableciendo en el art. 52 una cláusula general de limitación de los derechos.

25 El TJUE ha señalado que el derecho a la protección de datos de carácter personal no es un derecho absoluto, sino que se ha de considerar en relación con su función en la sociedad -Sentencia de 9.11.2010, C-92/09 y C-93/09, Volker und Markus Schecke y Eifert, Rec. 2010. Este Tribunal ha señalado reiteradamente que los límites a los derechos fundamentales solo están justificados si responden a objetivos de interés general perseguidos por la Comunidad y respetan el principio de proporcionalidad. En caso contrario, estos límites suponen una intervención desmesurada e intolerable que afecta a la propia esencia de los derechos. Cfr. el Considerando 139 de la propuesta de Reglamento, donde se cita la voluntad del presente Reglamento de observar otros derechos reconocidos en la Carta de los Derechos Fundamentales de la Unión Europea, como la libertad de pensamiento, de conciencia y de religión, la libertad de expresión y de información, la libertad de empresa o el derecho a la tutela judicial efectiva. Igualmente, los
Este sería el caso de la libertad de expresión, que justifica un régimen específico para los tratamientos de datos personales con fines periodísticos o de expresión literaria o artística que contemplan tanto el art. 80 de la propuesta de Reglamento como el art. 9 de la Directiva y que merece una atención más específica ${ }^{26}$. La libertad de expresión, especialmente cuando se efectúa con fines periodísticos, ha sido considerada tradicionalmente como una libertad preferente - un primus inter pares ${ }^{27}$ ya que este va-

elementos jurídicos de la propuesta de Reglamento -en concreto el apdo. 3.3 que contiene el "Resumen de las cuestiones relativas a los derechos fundamentales"- señala que otros derechos fundamentales potencialmente afectados y consagrados en la Carta son la libertad de expresión, la libertad de empresa, el derecho a la propiedad y, especialmente, la protección de la propiedad intelectual, la prohibición de toda discriminación, y, en particular, la ejercida por razón de raza, orígenes étnicos, características genéticas, religión o convicciones, opiniones políticas o de cualquier otro tipo, discapacidad u orientación sexual, los derechos del menor, el derecho a un alto nivel de protección de la salud humana, el derecho de acceso a los documentos o el derecho a la tutela judicial efectiva y a un juez imparcial.

Se debe valorar también el interés que ha mostrado por esta cuestión la Comisaria Europea de Justicia, Viviane Reding, que es periodista.

27 Así, el Tribunal Constitucional ha señalado, en Sentencia 171/1990, de 12 de noviembre, que: "Dada su función institucional, cuando se produzca una colisión de la libertad de información con el derecho a la intimidad y al honor aquélla goza, en general, de una posición preferente y las restricciones que de dicho conflicto puedan derivarse a la libertad de información deben interpretarse de tal modo que el contenido fundamental del derecho a la información no resulte, dada su jerarquía institucional desnaturalizado ni incorrectamente relativizado. En todo caso, el Tribunal Constitucional en la Sentencia 336/1993, de 15 de noviembre, sostiene en lo relativo a las relaciones entre la libertad de expresión y los derechos reconocidos en el art. 18 CE que "la ponderación entre los derechos constitucionales en conflicto requiere que se tenga en cuenta la posición prevalente -aunque no jerárquicaque respecto al consagrado en el art. 18.1 CE ocupan los derechos a la libre comunicación de información y a la libertad de expresión del art. 20.1 C.E. cuando su ejercicio tiene lugar dentro del ámbito constitucionalmente protegido, dado que estos constituyen no solo libertades individuales de cada ciudadano sino también la "garantía institucional de una opinión pública indisolublemente unida al pluralismo democrático". La jurisprudencia del Tribunal Constitucional ha señalado que la libertad de información ocupa una posición prevalente cuando se ejercita por un medio institucionalizado de creación de la opinión pública -cuestión importante, como se verá más adelante-; existe veracidad subjetiva -en el concepto desarrollado por el Tribunal Constitucional de buena praxis profesional del informador que le obliga a comprobar y contrastar de modo diligente los hechos sobre los que versa la información con carácter previo a su difusión (SSTC 6/1988, de 21 de enero; 105/1990, de 6 de junio; 240/1992, de 21 de 
Ior procedimental es básico para alcanzar una opinión pública libre, condición indispensable para una auténtica sociedad democrática y para limitar el poder ${ }^{28}$. La preferencia de la libertad de información sobre el derecho a la protección de datos personales es también una consecuencia lógica de la libertad ideológica, del valor pluralismo político y, en definitiva, del principio democrático. Esta preferencia de la libertad de información sobre la protección de datos personales también facilita la necesaria transparencia administrativa y la publicidad de la información administrativa aunque ésta contenga datos personales $^{29}$. Así, el art. 80 de la propuesta de

diciembre y 61/2004, de 19 de abril)-; se trata de asuntos públicos que son de interés general por las materias a las que se refieren o por las personas que intervienen y contribuye a la formación de la opinión pública (SSTC 105/1983, de 23 de noviembre; 107/1988, de 8 de junio; 132/1995, de 11 de septiembre); y las informaciones vertidas no incluyan expresiones injuriosas, vejatorias o insultos, que además son innecesarios para el mensaje que se quiere transmitir, aunque la Constitución no prohíba las expresiones hirientes, molestas o desabridas (STC 112/2000, de 5 de mayo, 49/2001, de 26 de febrero y 110/2000, de 5 de mayo).

28 Véase en esta dirección a ELY, que justifica el activismo procedimental -la preferencia de los valores procedimentales sobre los sustantivos- y representa una justificación dogmática de la jurisprudencia Warren. Cfr. Ely (1980, pp. 43-72); Aragón (1990); Troncoso 2000, pp. 450-454).

29 El acceso a información pública, además de ser elemento necesario para el ejercicio del derecho fundamental a la participación en asuntos públicos del art. $23 \mathrm{CE}$-otro valor procedimental imprescindible en una sociedad democrática-, es una exigencia en muchas ocasiones del derecho a comunicar o recibir información veraz por cualquier medio de difusión (art. 20.1.d CE), entendido no solo como un derecho a recibir información a través de los medios de comunicación, sino como un derecho a recibir toda la información accesible al público en general. Existe una clara conexión entre el derecho a comunicar y recibir información veraz y la garantía institucional de una opinión pública libre, que exigen la búsqueda y la comprobación de la información, con el derecho de acceso a los archivos y registros administrativos, especialmente cuando la solicitud de información administrativa la desarrollan medios de comunicación social. En este caso, el derecho de acceso a información administrativa por los medios de comunicación sería una garantía de la propia libertad de información. De esta forma, el art. 20.1.d CE no solo prohíbe que el Estado interfiera en la recepción de la información por parte de los ciudadanos -no solo sería un derecho de libertad que implicaría el respeto a la actividad de los medios de comunicación-, sino que establece una obligación a los poderes públicos de facilitar al público el libre acceso a la información administrativa -tendría una clara dimensión prestacional que obligaría a proporcionar
Reglamento permite a los Estados miembros disponer de exenciones o excepciones a los principios y derechos de protección de datos, a las obligaciones del responsable y del encargado, a la regulación de las transferencias de datos personales e incluso, a las competencias de las autoridades de control y a los mecanismos de cooperación y de coherencia "en el referente al tratamiento de datos personales efectuado exclusivamente con fines periodísticos o de expresión literaria o artística, para conciliar el de-

información-. Obviamente, no siempre las solicitudes de acceso de los ciudadanos están vinculados a la existencia de una opinión pública libre o de una sociedad democrática -lo que sí ocurre en el caso de los medios de comunicación-; ya que en muchas ocasiones se trata de un acceso instrumental para el ejercicio de otros derechos. En todo caso, el acceso a fuentes administrativas es más importante para configurar una opinión pública libre y una sociedad democrática avanzada -por estar estrechamente vinculada a los procesos de participación política- que la prevalencia de la libertad de expresión sobre el derecho al honor y a la intimidad de las personas en otros ámbitos, como aquellos de los que se ocupa la llamada "prensa del corazón". Sin embargo, el Tribunal Supremo en la Sentencia de 19 de mayo de 2003, que analizó la denegación del ejercicio del derecho de acceso de un periodista del Diario El Mundo a un expediente administrativo relativo a los créditos FAD concedidos a la empresa pública FOCOEX, ratificó la Sentencia de la Audiencia Nacional afirmando que el art. 20.1.d -que el recurrente había invocado a través del procedimiento de amparo contenciosono puede confundirse con el derecho de acceso a archivos y registros administrativos del art. 105.b) CE. Hasta ahora, el Tribunal Constitucional ha señalado en la Sentencia 161/1988, de 20 de septiembre, que las reglas y principios contenidos, entre otros, en el art. 105.b de la Constitución "son inadecuadas para fundamentar una petición de amparo en cuanto que en ninguno de ellos se reconocen derechos fundamentales y libertades políticas de los incluidos como amparables en el artículo 53.2 de la Constitución". En todo caso, el derecho de acceso a información administrativa, aun considerado como derecho constitucional diferente de la libertad de información, tiene un carácter de libertad preferente -preferred freedoms-, al ser un valor procedimental necesario para una sociedad abierta y para el funcionamiento de un Estado democrático. Como señaló Ely (1980), los valores procedimentales -entre los que se podría incluir el acceso a la información pública- tienen preferencia sobre los valores sustantivos, ya que estos valores procedimentales, al permitir mantener abiertos los canales de participación, contribuyen a que los valores sustantivos sean reflejo de la voluntad general. Cfr. más ampliamente sobre la cuestión Villaverde (1995a; 1995b); Fernández, (1997, pp. 350-357); Pomed (1989); Mestre 1993); Guichot (2010, pp. 154-181). Sin embargo, la STJCE, de 16.12.2008, as. Satakunnan Markkinapörssi y Satamedia (C-73/07, Rec. 2008, p. I-9831) señala que la publicación en forma de catálogo de los datos fiscales de ciudadanos finlandeses, incluidos los datos sobre sus ingresos y patrimonio, si se trata de datos procedentes de documentos públicos, puede considerarse una actividad periodística si su finalidad es divulgar al público información, opiniones o ideas por cualquier medio de transmisión. 
recho a la protección de datos personales con las normas que rigen la libertad de expresión" 30 . De esta forma, el reconocimiento del derecho al olvido en Internet, que obliga al responsable del tratamiento a suprimir los datos sin demora, se encuentra limitado por el ejercicio de la libertad de expresión que permite la conservación de los datos personales (art. 17.3.a), lo que supone la continuidad de la publicación de la información en medios de comunicación digitales. También, la Directiva 95/46/CE había establecido una restricción importante del derecho fundamental a la protección de datos personales en beneficio de la libertad de información y de expresión cuando el tratamiento de datos personales tenga fines periodísticos o de expresión artística o literaria. Así, los Considerandos 17 y 37 de la Directiva señalan que los principios de la misma deben ser aplicados de forma restringida o pueden justificarse excepciones cuando se esté en presencia de tratamientos de datos personales, incluido de sonido o imágenes, aplicados con fines periodísticos o de expresión literaria o artística, en particular en el sector audiovisual, siempre que esto sea necesario para conciliar los derechos fundamentales de la persona con la libertad de expresión y, en particular, la libertad de recibir o comunicar informaciones garantizado en el art. 10 del $\mathrm{CEDH}^{31}$. Corresponde a los Estados ponderar el derecho fundamental a la protección de datos y la libertad de expresión

30 Cfr. Paissan (2003, pp. 17-47); Cotino (2010, pp. 295-322); Arias (año, pp. 560-577); Cazurro (2012)

31 La Memoria explicativa sobre el Convenio 108 señala la libertad de expresión como uno de "los derechos y libertades de los demás", para cuya protección los legisladores nacionales, de conformidad con lo dispuesto en la letra b) del apartado 2, del artículo 9 del Convenio, pueden apartarse de los principios básicos de la protección de datos. y de información, estableciendo las excepciones o restricciones necesarias a la legislación de protección de datos que permitan el ejercicio de estos derechos. Así, en esta dirección el art. 9 de la Directiva "Tratamiento de datos personales y libertad de expresión" establece que "en lo referente al tratamiento de datos personales con fines exclusivamente periodísticos o de expresión artística o literaria, los Estados miembros establecerán, respecto de las disposiciones del presente capítulo, del capítulo IV y del capítulo VI, exenciones y excepciones sólo en la medida en que resulten necesarias para conciliar el derecho a la intimidad con las normas que rigen la libertad de expresión". También, en virtud de la Directiva 95/46/CE no puede exigirse el consentimiento del interesado para el tratamiento de sus datos personales -también de su imagen y sonido - o para la cesión o publicación de la información - de ahí también el límite al derecho al olvido y a la supresión- cuando estas se llevan a cabo exclusivamente con fines periodísticos o de expresión literaria o artística. Estas excepciones previstas en las leyes de los países europeos podrían afectar también, como señalan los Considerandos de la Directiva, por ejemplo, a las transferencias de datos a terceros países o a las competencias de las autoridades de control.

Este es uno de los ámbitos donde, a juicio de la Comisión, "least convergence can be discernid"32. A pesar de ello, la propuesta de

32 Cfr. Analysis and impact study on the implementation of Directive EC 95/46 in Member States, http://ec.europa.eu/justice_home/fsj/privacy/ lawreport/index_en.htm.. La Recomendación 1/1997, de 27 de febrero, del Grupo de Trabajo del Artículo 29 sobre la normativa de protección de datos y los medios de comunicación señalaba que en aquel momento las diferentes legislaciones nacionales habían abordado la 
Reglamento respeta el amplio margen de maniobra que la Directiva concedía a los Estados al ser una cuestión nuclear del Estado constitucional, correspondiéndoles a los Estados miembros establecer las excepciones a los principios y derechos de protección de datos en este ámbito con la finalidad de conceder una protección preferente a la libertad de expresión y de información, quedando obligados a notificar a la Comisión las disposiciones legislativas que se adopten para establecer estas excepciones -art. 80.2 de la propuesta de Reglamento-. Así, por ejemplo, la LOPD no hace ninguna referencia a los tratamientos de datos personales para el ejercicio de la libertad de información y de expresión -no establece un régimen de excepciones a la aplicación de la normativa de protección de datos en relación con los tratamientos con fines periodísticos-, conteniendo únicamente previsiones relativas a la publicación de datos personales por los medios de comunicación social a los que atribuye el carácter de fuente accesible al público ${ }^{33}$ por lo que no es necesa-

cuestión con arreglo a uno de los enfoques siguientes: “a) En algunos casos, la normativa relativa a la protección de datos no contempla exención expresa alguna de la aplicación de sus disposiciones para los medios de comunicación. Tal es la situación actual en Bélgica, Portugal, Suecia, Reino Unido y España - en nuestro país, tal como hemos visto, los medios de comunicación son contemplados como fuentes accesibles al público, lo que suponía una concretización de la previsión del art. 7.f) de la Directiva 95/46/CE-. b) En otros casos, los medios de comunicación están exentos de la aplicación de varias disposiciones de la normativa de protección de datos. Tal es la situación actual en el caso de Alemania, Francia, los Países Bajos, Austria y Finlandia. El proyecto de normativa italiana prevé excepciones similares. c) Y, en otros casos, los medios de comunicación quedan exceptuados de la normativa general de protección de datos y están regulados por disposiciones específicas en este ámbito. Es el caso de Dinamarca, para todos los medios de comunicación, y de Alemania, en relación con las empresas públicas de radiodifusión, que están cubiertas por las normativas federal o de los estados federados de protección de datos, pero están sujetas disposiciones específicas de protección de datos establecidas en los tratados interestatales que las regulan". rio el consentimiento del interesado para el tratamiento y para la cesión (arts. 6.2 y 11.2.b). El hecho de que la LOPD no mencione los tratamientos de datos personales llevados a cabo por los medios de comunicación no significa que estos tratamientos se encuentren excluidos del ámbito de aplicación de la legislación ${ }^{34}$. Se debe señalar que en España no hay ninguna Ley que tenga como objeto específico regular la libertad de información -aunque sí se aprobó tempranamente la Ley Orgánica 1/1982, de 5 de mayo, de protección civil del derecho al honor, a la intimidad personal y familiar y a la propia imagen-. La ausencia de regulación de la libertad de información y de expresión es consecuencia de una voluntad consciente del legislador de no limitar en exceso el ejercicio de este derecho fundamental, dejando la definición de sus límites a la doctrina del Tribunal Constitucional y la resolución de los conflictos a la jurisdicción ordinaria. En todo caso, la propia Constitución Española, al tiempo que reconoce la libertad de expresión y de información, establece que estas libertades tienen un límite expreso en el derecho al honor, a la intimidad y a la imagen (art. 20.4 CE).

Por tanto, la libertad de expresión y de información no es tampoco un derecho absoluto y no puede suprimir el derecho a la intimidad y a la protección de datos personales que se fundamentan en la dignidad de la persona y que son necesarios para mantener una calidad de vida

De hecho, no se encuentran estos tratamientos entre los excluidos del ámbito de aplicación de la LOPD ni tampoco entre los remitidos a su legislación específica (art. 2 LOPD). 
humana ${ }^{35}$. Como se ha señalado en otra ocasión, la protección de datos personales, como todo derecho fundamental, tiene una vertiente subjetiva, en este caso muy importante, ya que su objeto es la información sobre personas. No obstante, es necesario hacer hincapié en que la protección de los datos personales, si bien tiene como beneficiario directo a la persona interesada, no afecta solo al sujeto individual sino a toda la sociedad en su conjunto ya que el ejercicio de los derechos y libertades - la capacidad de decisión y la autonomía- exige preservar un ámbito de privacidad. Hay que superar una concepción individualista de este derecho, derivada de una lógica iusprivatista y propia del constitucionalismo liberal, que analiza el derecho fundamental a la protección de datos personales como un derecho individual, vinculado al derecho de propiedad, que concierne principalmente a las partes interesadas a las que atribuye el control de la propia información personal. Sin negar la función social de la libertad de información, es necesario afirmar que la protección de datos personales "es un elemento esencial y objetivo que afecta al conjunto de la sociedad y concierne a la calidad de una democracia que demanda ciudadanos libres y con capacidad de decisión. Existe un interés público en el respeto a la protección de los datos personales al ser también un instituto de garantía de otros derechos fundamentales, de tal manera que protegiendo los datos personales frente a los tratamientos

35 Así, el Tribunal Constitucional en la Sentencia 57/1994, de 28 de febrero, lo reconoce como un derecho "estrictamente vinculado a la propia personalidad y que deriva, sin duda, de la dignidad de la persona humana [...] entrañando la intimidad personal constitucionalmente garantizada la existencia de un ámbito propio y reservado frente a la acción y el conocimiento de los demás, necesario -según las pautas de nuestra cultura- para mantener una calidad de vida humana". estamos protegiendo al mismo tiempo el ordenamiento constitucional" ${ }^{36}$. Por este motivo, el ejercicio de la libertad de información debe respetar también principios y derechos de protección de datos personales. De esta forma, no se trata de exceptuar por completo la normativa de protección de datos personales en este ámbito, sino de establecer solo aquellas restricciones necesarias que faciliten la libertad de información y de expresión.

Hay que tener en cuenta que tanto la propuesta de Reglamento como la Directiva protegen la libertad de expresión que se materializa a través de tratamientos de datos personales "con fines periodísticos o de expresión literaria o artística" y no solo la libertad de información ${ }^{37}$, a diferencia de nuestro Tribunal Constitucional que ha señalado que solo ocupa una posición preferente el derecho a una comunicación pública libre que desarrollan los medios de comunicación - los medios institucionalizados de creación de la opinión pública- y los periodistas, y no la libertad de expresión genérica ${ }^{38}$. Así, la pro-

36 Sobre la protección de datos personales como instituto de garantía de otros derechos fundamentales, cfr. autor (2010, pp. 27-40).

37 Tanto el Considerando 121 de la propuesta de Reglamento como el Considerando 37 de la Directiva señalan la necesidad de conciliar la protección de datos con la libertad de expresión, si bien hacen una mención particular al derecho a recibir o comunicar informaciones, como se garantiza en el art. 11 de la Carta de los Derechos Fundamentales de la Unión Europea y en el art. $10 \mathrm{CEDH}$, respectivamente. En todo caso, el desarrollo de Internet -de blogs, de la web 2.0- ha hecho que cualquier persona -y no solo algunos profesionales- tenga la capacidad de informar y de que esta información llegue al conjunto de la sociedad.

38 El Tribunal Constitucional señala que la libertad de información "alcanza un máximo nivel cuando [...] es ejercitada por los profesionales de la información a través del vehículo institucionalizado de formación de la opinión pública que es la prensa, entendida en su más amplia acepción" (SSTC 165/1987, de 27 de octubre, y 29/2009, de 26 de enero). Así, Agustín Puente (2008), Jefe del Gabinete Jurídico de la AEPD, afirmó en la Primera Sesión Anual Abierta de la AEPD, de 22 de abril 
puesta de Reglamento (art. 80), al igual que la Directiva (art. 9), no solo permiten excepciones en los tratamientos con fines periodísticos sino también en los de expresión literaria o artística, señalando la necesidad de conciliar el derecho a la protección de datos personales con las normas que rigen la libertad de expresión, todo ello en preceptos titulados "tratamiento de datos personales y libertad de expresión". También señala que el derecho al olvido en Internet se encuentra limitado por la libertad de expresión (art. 17.3.a). El Considerando 121 de la propuesta de Reglamento señala que "con objeto de tomar en consideración la importancia del derecho a la libertad de expresión en toda sociedad democrática, es necesario interpretar en

de 2008 que "podrán considerarse incluidos en fuentes accesibles al público los datos que hayan sido objeto de difusión a través de prensa, radio y televisión (convencional o digital). Las revistas puramente científicas no deberían considerarse fuentes accesibles al público a los efectos de la aplicación de la LOPD. Internet no es, a los efectos de protección de datos, un medio de comunicación social sino un canal de comunicación, por lo que no es fuente accesible al público". En esa dirección, la Resolución de la AEPD 224/2007, de 19 de abril señala que "los datos personales contenidos en Internet no se consideran dentro de la categoría de medio de comunicación, con independencia de que en el ámbito penal, el Tribunal Supremo pueda entender que los delitos de calumnias e injurias cometidos a través de Internet, se asimilen a los que se produzcan a través de medios de comunicación". Para la Agencia no es equiparable un medio de comunicación institucionalizado y profesionalizado, con el periodismo ciudadano con presencia en la red y mucho menos con extender el concepto a todo lo difundido en Internet. La Agencia solo aplica la excepción de la libertad de información si la ejercen periodistas profesionales, con un fin periodístico y desarrollan una función social. Cazurro (2012, pp. 156-157) analiza muchas Resoluciones de la AEPD que terminan con un archivo de actuaciones en virtud de la prevalencia de la libertad de expresión y de información sobre el derecho fundamental a la protección de datos personales, señalando que la inmensa mayoría de los denunciados son medios de comunicación institucionalizados - diarios, ediciones digitales de periódicos-. Este autor señala que muy pocas veces se aplican las excepciones relativas a la libertad de expresión y de información a las publicaciones hechas en páginas web corporativas. Ya hemos visto antes como la AEPD, en su Informe 342/2008, no considera a las páginas web como fuentes accesibles al público. Tiene sentido la interpretación restrictiva de la categoría de fuentes accesibles al suponer un límite a un derecho fundamental. Sin embargo, no puede hacerse una interpretación igualmente restrictiva del concepto de medio de comunicación social como fuente accesible al público porque en este caso, a diferencia del resto de las fuentes -diarios oficiales, repertorios telefónicos-, se puede estar ejerciendo las libertades reconocidas en el art. $20 \mathrm{CE}$. sentido amplio conceptos relativos a dicha libertad, como el periodismo. Por consiguiente, los Estados miembros deben clasificar determinadas actividades como "periodísticas" a efectos de las exenciones y excepciones que se han de establecer al amparo del presente Reglamento si el objeto de dichas actividades es la comunicación al público de información, opiniones o ideas, con independencia del medio que se emplee para difundirlas. No tienen por qué circunscribirse a empresas de comunicación y pueden desarrollarse con o sin ánimo de lucro"39. Este planteamiento es coherente con el reconocimiento constitucional del derecho a expresar y difundir libremente pensamientos, ideas y opiniones, mediante la palabra, el escrito o cualquier otro medio de reproducción (art. 20.1.a). Esto obliga a modificar el criterio restrictivo en nuestro país, que solo aplicaba la excepción de los tratamientos de datos personales con fines periodísticos a los que desarrollaban los medios de comunicación institucionalizados -a las empresas de comunicación con ánimo de lucro y a los profesionales del periodismo- en virtud de su calificación en el art. 3.j LOPD, para adoptar ahora una doctrina que incluya también los tratamientos de datos personales que Ilevan a cabo los ciudadanos con fines periodísticos que pretenden comunicar al público información, opiniones o ideas, con independencia del me-

39 La propuesta de Reglamento tiene en cuenta la interpretación del art. 9 de la Directiva 95/46/CE por la STJUE, de 16.12.2008, as. Satakunnan Markkinapörssi y Satamedia cit., donde se señalaba que la publicación de documentos públicos puede considerarse actividades periodísticas si su finalidad es divulgar al público información, opiniones o ideas por cualquier medio de transmisión, no estando reservada la excepción de la Directiva a las empresas de comunicación que ejercen esta actividad con ánimo de lucro. Recientemente, la Sentencia de la Audiencia Nacional, de 11 de abril de 2012, ha revocado una Resolución de la AEPD entendiendo que la publicación de determinados datos en una página web estaba amparada por la libertad de expresión. 
dio que empleen para difundirlos -aunque se haga sin ánimo de lucro-, e incluso para acoger aquellos tratamientos que son plasmación de una libertad de expresión más genérica, que incluiría la literaria o artística, todo ello para favorecer la libertad de expresión en la red. Lógicamente, que cualquier persona pueda esgrimir el ejercicio de la libertad de expresión para limitar el derecho a la protección de datos personales obliga, por una parte, a delimitar cuándo se está ejerciendo realmente la libertad de expresión a través de un tratamiento de datos personales; y por otra, a llevar a cabo una especial labor de ponderación entre derechos fundamentales y a la aplicación del principio de proporcionalidad que garantice el equilibrio entre ambos derechos, algo que no era posible con la calificación de los medios de comunicación como fuentes accesibles al público ${ }^{40}$.

40 El problema reside en que la calificación de una publicación como medio de comunicación supone en virtud de la LOPD su consideración de fuente accesible al público y, por tanto, la imposibilidad de llevar a cabo una actividad de ponderación. Esto ha llevado a la Agencia Española a mantener una interpretación restrictiva del concepto de medio de comunicación y de las personas que pueden alegar el ejercicio de la libertad de expresión e información para exceptuar el derecho a la protección de datos personales. Hay que tener en cuenta, de nuevo, que en España no se encuentra traspuesta la previsión del art. 7.f de la Directiva -que tiene efecto directo (cfr. "Hacia un nuevo marco normativo", loc. cit. apdo. IV.B y C)-, que permite el tratamiento para la satisfacción de un interés legítimo perseguido por el responsable o por el tercero a quien se comunique sus datos y que facilita una ponderación con los derechos de los interesados a la protección de sus datos personales; sino que solo está prevista la existencia de unas fuentes accesibles al público, lo que suprime el consentimiento para el tratamiento y para la cesión. Esto ha obligado a una interpretación restrictiva de estas fuentes accesibles al público incluidas en el art. 3.j LOPD y en el art. 7 RPDP. Una interpretación muy amplia del concepto de medios de comunicación, que permitiera a cualquier persona el tratamiento y la publicación de datos personales sin consentimiento con solo esgrimir el ejercicio de la libertad de expresión, afectaría al contenido esencial del derecho fundamental a la protección de datos personales. También, se ha interpretado de manera restrictiva la excepción al consentimiento para el tratamiento de datos personales y para las cesiones en relación con la actividad investigadora que se encuentra en la legislación universitaria y en el art. 11.2.e de la LOPD -también en el art. 13.2 de la Directiva-, aplicándola solo a la investigación institucional de los profesores en las universidades públicas y no a su actividad de investigación individual por la imposibilidad de llevar a cabo la ponderación, una cuestión que aborda ahora con acier-
Tanto la propuesta de Reglamento (art. 80.1) como la Directiva (art. 9) exigen para beneficiarse de la excepción que los tratamientos de datos personales se realicen "exclusivamente con estos fines periodísticos o de expresión literaria o artística". Así, que el régimen especial de los tratamientos de datos personales se aplique no en virtud del sujeto - que sea una empresa de comunicación o un periodista- sino de la finalidad de los tratamientos, sea cual sea la cualidad del sujeto que lo haga o del medio que emplee para difundirlas, obliga a prestar una atención especial a que realmente "el objeto de dichas actividades [sea] la comunicación al público de información, opiniones o ideas" (Considerando 121) ${ }^{41}$. Las excepciones al derecho a la protección de datos que se aplican a los tratamientos con fines periodísticos se justifican en que estos tratamientos son una materialización del "derecho a la libertad de expresión, y, en especial, del derecho de recibir o de comunicar informaciones, como se garantiza especialmen-

to el art. 83 de la propuesta de Reglamento. Hay que señalar que, si bien las excepciones al derecho a la protección de datos personales por tratamientos personales vinculados a la libertad de expresión tienen acogida en el art. 80 de la propuesta de Reglamento -y en el art. 9 de la Directiva-, también le sería de aplicación la referencia a la satisfacción de un interés legítimo del art. 6.1.f de la Propuesta de Reglamento -no el cumplimiento de una misión de interés público del art. 6.1.e), que es solo aplicable a las Administraciones Públicas-, lo que permite la vigencia del principio de proporcionalidad. Mientras que se aprueba la propuesta de Reglamento, el efecto directo del art. 7.f de la Directiva permite una interpretación más amplia del concepto de medio de comunicación, coherente con el ejercicio de las libertades del art. $20 \mathrm{CE}$, y que al mismo tiempo facilita la ponderación y el equilibrio con el derecho a la protección de datos personales, que su calificación automática como fuente accesible al público impedía. Hay que tener en cuenta que el art. 9 de la Directiva prevé también una actividad de ponderación que no ha podido desarrollarse con la previsión del art. 3.j LOPD.

41 La STJUE, de 16.12.2008, as. Satakunnan Markkinapörssi y Satamedia cit. también aplicaba la excepción del art. 9 de la Directiva 95/46/ CE a los tratamiento de datos efectuados exclusivamente con fines periodísticos, si tales actividades se ejercen exclusivamente con la finalidad de divulgar al público información, opiniones o ideas por cualquier medio de transmisión. 
te en el artículo 11 de la Carta de los Derechos Fundamentales", dada "la importancia del derecho a la libertad de expresión en toda sociedad democrática" -Considerando 121-. Como ha señalado la STC 171/1990 de 12 de noviembre, la posición preferente de la libertad de información frente a otros derechos fundamentales no es absoluta, puesto que "si viene reconocido como garantía de la opinión pública, solamente puede legitimar las intromisiones en otros derechos fundamentales que guarden congruencia con esa finalidad, es decir, que resulten relevantes para la formación de la opinión pública sobre asuntos de interés general"42. La prevalencia de estos derechos se da si se ejercen en su ámbito constitucional protegido, que es la garantía institucional de una opinión pública libre. Por tanto, es necesario que el tratamiento de datos personales que pretenda exceptuarse del régimen general de protección de datos en virtud del ejercicio de la libertad de expresión tenga "exclusivamente" esa vocación de comunicar al público información, opinión o ideas y, contribuir, por tanto, a una opinión pública libre

42 Así, como señala la STC 171/1990 de 12 de noviembre, carecen de tal efecto legitimador cuando "las libertades de expresión y de información se ejerciten de manera desmesurada y exorbitante del fin en atención al cual la Constitución le concede su protección preferente. De ello se deriva que la legitimidad de las intromisiones en el honor e intimidad personal requiere no solo que la información cumpla la condición de la veracidad, sino también que su contenido se desenvuelva en el marco del interés general del asunto al que se refiere; de otra forma, el derecho de información se convertiría en una cobertura formal para, excediendo el discurso público en el que debe desenvolverse, atentar sin límite alguno y con abuso de derecho, al honor, y la intimidad de las personas, con afirmaciones, expresiones o valoraciones que resulten injustificadas por carecer de valor alguno para la formación de la opinión pública sobre el asunto de interés general que es objeto de la información. El efecto legitimador del derecho de información, que se deriva de su valor preferente, requiere, por consiguiente, no sólo que la información sea veraz -requisito necesario directamente exigido por la propia Constitución, pero no suficiente-, sino que la información tenga relevancia pública, lo cual conlleva que la información veraz que carece de ella no merece la especial protección constitucional". en una sociedad democrática. Lógicamente, el abandono del criterio del sujeto -que sea un medio de comunicación institucionalizado o periodistas profesionales quienes que ejerzan la libertad de información- por el de la finalidad del tratamiento, que permite a cualquier persona apelar al ejercicio de la libertad de expresión en Internet, fomenta el pluralismo informativo en una sociedad democrática pero también obliga a llevar a cabo una cuidadosa labor de delimitación en cada supuesto concreto ${ }^{43}$. Además, la exigencia normativa de la excepción al régimen general de protección de datos personales solo vaya destinada a los tratamientos de datos personales que se realicen "exclusivamente con estos fines periodísticos o de expresión literaria o artística", también supone un importante límite para las empresas de comunicación. Así, no estarían protegidos por la libertad de expresión y de información aquellos tratamientos de datos personales que llevan a cabo los medios de comunicación institucionalizados que no tienen en sí mismo un fin periodístico o de expresión literaria o artística, como son, por ejemplo, los tratamientos en el ámbito de los recursos humanos, las promociones comerciales y de marketing, los tratamientos de las personas físicas suscriptoras ${ }^{44} u$ otros tratamientos, muchos de ellos masivos, como son los relativos a la parti-

43 Lógicamente, el abandono del criterio del sujeto es también consecuencia de que Internet, como medio y estructura de comunicación, difumina las diferencias entre los profesionales de la información que desarrollan el periodismo institucional y los particulares que ejercen la libertad de expresión.

44 Los datos de personas físicas suscriptoras de medios de comunicación no solo no están excluidos de la normativa de protección de datos sino que merecen una protección especial porque pueden servir para establecer perfiles e, incluso, en ocasiones, revelar ideología, religión u orientación sexual, una cuestión que no podemos abordar aquí. 
cipación en concursos, juegos o sorteos y que no tienen ni un fin periodístico ni de expresión literaria o artística ${ }^{45}$. Por tanto, estos tratamientos están sometidos al régimen general de protección de datos personales.

Además, es necesario llevar a cabo una ponderación entre la libertad de expresión y de información y el derecho a la protección de datos personales, aplicando el principio de proporcionalidad, de forma que se garantice el equilibrio entre ambos derechos. No se trata de exceptuar por completo la normativa de protección de datos personales a los tratamientos de datos personales efectuados con fines exclusivamente periodísticos o de expresión literaria o artística sino de establecer solo aquellas restricciones

45 La Agencia Española impuso una sanción de 1,08 millones de euros a la productora Zeppelin Televisión $S A$, por el incumplimiento de la LOPD en el tratamiento de 7.000 candidatos a participar en programa Gran Hermano, que emitía Tele 5. El Tribunal Supremo, en la Sentencia de 17 de abril de 2007, confirmó la sanción -que previamente había sido ratificada por la Audiencia Nacional-. Este tratamiento de datos personales de la productora no se realizaba exclusivamente con fines periodísticos o de expresión literaria o artística y que no estaba excluido de la vigencia de los principios y derechos de protección de datos en virtud de la libertad de información y de expresión, sin perjuicio de que se le apliquen otras excepciones relativas a la existencia de una relación jurídica (art. 11.2.c LOPD). La productora incumplió su obligación de implantar medidas de seguridad lo que permitió que los datos relativos a un "considerable número de aspirantes" a participar en el concurso televisivo acabaran apareciendo en Internet. La productora no respetó el principio de calidad, recabando, además, datos personales sin cumplir el principio de información y cediéndolos a empresas con las que no le unía ningún lazo contractual. El Tribunal señaló que la tramitación del expediente sancionador puso de manifiesto "el más completo desprecio (de la productora televisiva) hacia la exigencia del consentimiento consciente e informado de los afectados para que sus datos personales (información relativa a gustos, ideología, creencias religiosas, raza, salud o vida sexual) fueran almacenados, tratados y cedidos". Así, se señala que "la participación en un programa, incluso en el de Gran Hermano, no puede 'despojar' a un ciudadano de su derecho a la intimidad, porque su libertad sigue intacta y conserva el pleno derecho a que nadie trate, ceda o revele sus datos personales". La AEPD desarrolló en el año 2002 una Inspección Sectorial de Oficio, en el sector de Concursos, juegos y sorteos de televisión, que finalizó con una Recomendación que los somete a la normativa general de protección de datos y donde se señala que "no se recabarán datos personales cuyo conocimiento por parte del responsable no esté justificado por la finalidad para la que se recaban y de la cual el usuario no haya sido previamente informado". necesarias que faciliten la libertad de información y de expresión o eviten ponerla en peligro. La Directiva establece que no caben todas las exenciones y excepciones sino "sólo [aquellas] en la medida en que resulten necesarias para conciliar el derecho a la intimidad con las normas que rigen la libertad de expresión" (art. 9 y Considerando 37). Además, el Considerando 37 de la Directiva, por una parte, no admite excepciones a las medidas que garanticen la seguridad de los tratamientos y, por otra, si bien acepta excepciones en lo relativo a las competencias de las autoridades de control, señala que debe concederse a estas "al menos una serie de competencias a posteriori como por ejemplo publicar periódicamente un informe al respecto o bien iniciar procedimientos legales ante las autoridades judiciales". La regulación que hace la propuesta de Reglamento es bastante semejante, aunque la Directiva es algo más garantista, porque reitera explícitamente el juicio de necesidad para valorar la proporcionalidad de la injerencia y limita las materias sujetas al régimen de excepciones. El art. 80 de la propuesta de Reglamento menciona la necesidad de establecer excepciones o exenciones "para conciliar el derecho a la protección de los datos de carácter personal con las normas que rigen la libertad de expresión". Las excepciones y exenciones que se mencionan expresamente "son las relativas a los principios generales, los derechos del interesado, el responsable y encargado del tratamiento, la transferencia de datos a terceros países u organizaciones internacionales, las autoridades de control independientes, así como en la cooperación y la coherencia". Le corresponde a los Estados miembros adoptar las me- 
didas legislativas "necesarias a efectos de equilibrar estos derechos" (Considerando 121). Así, es lógica la excepción al principio de consentimiento del interesado cuya exigencia haría imposible el ejercicio de la libertad de expresión. De hecho, las previsiones de la propuesta de Reglamento y de la Directiva deben entenderse principalmente como supuestos de legitimación del tratamiento para fines periodísticos o de expresión literaria o artística, y, por tanto, como excepciones al consentimiento del interesado. La LOPD, al considerar los tratamientos de los medios de comunicación como fuentes accesibles al público, ha establecido la excepción del consentimiento para el tratamiento y para la cesión (arts. 6.2 y 11.2.c LOPD). Algo semejante puede decirse de la necesidad de establecer límites al principio de información en los tratamientos con fines periodísticos o de expresión literaria o artística.

La excepción al derecho del interesado a la cancelación de sus datos personales objeto de tratamiento es, también, algo consustancial al ejercicio de las libertades reconocidas en el art. 20 CE. Esto es de especial aplicación al derecho al olvido en Internet. De hecho, el Considerando 121 de la propuesta de Reglamento señala que estas excepciones a la protección de datos personales "debe[n] aplicarse en particular al tratamiento de los datos personales en el ámbito audiovisual y en los archivos de noticias y hemerotecas". Así, la propuesta de Reglamento establece como límite del derecho del interesado a que el responsable del tratamiento suprima los datos personales que le conciernen y se abstenga de utilizarlos, que la "conservación de los datos sea necesaria para el ejercicio de la libertad de expresión" (art. 17.3.a). De esta forma, le corresponde al medio de comunicación o a la persona que trata datos personales con fines periodísticos o con fines de expresión literaria o artística decidir si mantiene publicada la información accesible en Internet porque continúa el interés público o su relevancia para formar la opinión pública o limitar su indexación ${ }^{46}$. Lógicamente, esta decisión puede verse motivada por el ejercicio por el interesado de los derechos de rectificación, oposición y cancelación, alegando los criterios que más adelante señalaremos -tratamiento de datos excesivos, ausencia de interés público por la materia o por las personas a las que se refiere, falta de veracidad, expresiones vejatorias, etc. - - Como se señala más adelante, le corresponde al legislador nacional regular sistemáticamente el ejercicio del derecho de rectificación que forma parte de los derechos de protección de datos personales frente a los tratamientos con fines periodísticos o de libertad de expresión, con el derecho de rectificación, que se encuentra regulado en la Ley Orgánica 2/1984, de 26 de marzo. Lógicamente, la determinación de la rectificación o de la supresión no afecta a la versión en papel, sino a la versión electrónica -a una parte de la versión electrónica a la que ya no se le da publicidad-. Ya se ha señalado anteriormente que la regulación del derecho al olvido de la propuesta de Reglamento contempla la posibilidad de que el responsable del tratamiento, en lugar a pro-

Para M. Carrillo (2010) "la justificación jurídica se fundamenta en la veracidad y el interés público de la información que aparece en la red. Porque lo que fue de interés público en un momento determinado -la comisión de un delito- no puede desaparecer de la historia. De lo contrario estaríamos ante una falsedad". 
ceder a la supresión, limite el tratamiento de los datos $-\mathrm{y}$, por tanto, a nuestro juicio, limite la publicidad - cuando el interesado impugne la exactitud de los datos -durante el plazo que permita al responsable del tratamiento verificar la exactitud de los datos-; o cuando el responsable del tratamiento "ya no necesite los datos personales para la realización de su misión" (art. 17.4). Además, la propuesta de Reglamento obliga al responsable del tratamiento a llevar a cabo un examen periódico de la necesidad de conservar los datos (art. 17.7). Todos estas previsiones legales facilitan al responsable del tratamiento llevar a cabo una actividad de ponderación acerca del mantenimiento de la publicidad de la información y su accesibilidad a los buscadores, aplicando el principio de proporcionalidad para evitar los tratamientos excesivos que suponga una injerencia excesiva en los derechos de las personas ${ }^{47}$. Estas cuestiones deben ser abordadas principalmente a través de la autorregulación. Lógicamente, como he señalado antes, esta actividad de ponderación le corresponde al responsable del tratamiento, esto es, al medio de comunicación o a la persona que lleva a cabo el tratamiento de datos personales con fines periodísticos o de expresión literaria o artística y que ha hecho pública la información; no, obviamente, al motor de búsqueda.

La propuesta de Reglamento también establece que esta previsión "no debe llevar a los Es-

47 Hemos desarrollado en otro momento los criterios que delimitan cuándo la publicación de datos personales por la Administración Pública supone un tratamiento excesivo para la finalidad y debe bloquearse o cancelarse -cfr. autor (año, pp. 768-780)-. Sin embargo, estos criterios no son igualmente trasladables a los tratamientos de datos personales con fines periodísticos o de libertad de expresión porque estos suponen el ejercicio de una libertad preferente. tados miembros a establecer exenciones de las demás disposiciones del presente Reglamento" (art. 80.1). De hecho, hay exigencias de la normativa de protección de datos personales que no solo no perjudican el ejercicio de la libertad de expresión y de información sino que lo garantizan, como son las relativas a las normas de seguridad, que mencionaba expresamente la Directiva ${ }^{48}$. También sería de aplicación -en este caso a los medios de comunicación institucionalizados y a las empresas de comunicaciónmuchas de las obligaciones que la propuesta de Reglamento establece para el responsable del tratamiento como es la conservación de la documentación de los tratamientos, la realización de la evaluación de impacto en la privacidad o la designación de un delegado de protección de datos, cuyo cumplimiento en nada perjudica el ejercicio de la libertad de expresión ${ }^{49}$. Los responsables de los tratamientos también deben contestar a los interesados en el ejercicio de sus derechos de acceso, rectificación, cancelación y

48 Así, es necesario aplicar medidas de seguridad para garantizar la integridad e inalterabilidad de lo publicado en medios de comunicación en Internet -evitando ataques informáticos que modifiquen la información-. También es necesario implantar medidas de seguridad a los tratamientos de datos personales sobre informaciones aún no publicadas, aunque sea complicado el establecimiento de algunas de estas, como los controles de acceso, por la forma de trabajar de los periodistas que no es individual. Obviamente, no tiene sentido aplicar medidas de seguridad que garanticen la confidencialidad de la información cuando esta esté siendo publicada en abierto en Internet -por la misma razón que no tiene sentido exigir medidas de seguridad de nivel alto a los ficheros internos de diputados y senadores de las Cámaras si esta información debe publicarse sin consentimiento en virtud de la función de representación política-, además, se trata de datos que el interesado ha hecho manifiestamente públicos (art. 9.2.e de la propuesta de Reglamento).

49 De hecho, los medios de comunicación como las fuentes accesibles al público tenían la obligación de notificación de los tratamientos. Téngase en cuenta que incluso los responsables policiales de los ficheros para la investigación del terrorismo y de formas graves de delincuencia organizada debian comunicar previamente su existencia, sus características generales y su finalidad a la Agencia de Protección de Datos (art. 2.2.c LOPD). 
oposición, aunque sea, para desestimar la solicitud. Lógicamente, los tratamientos de datos personales por los medios de comunicación, pese a que se encuentren sustentados por la libertad de información y tengan el carácter de fuentes accesibles al público en nuestro país, están sometidos al control judicial ${ }^{50}$.

Mención específica merece el respeto al principio de calidad en los tratamientos de datos personales con fines periodísticos o de expresión literaria o artística. De hecho, la ponderación entre la libertad de expresión y el derecho a la protección de datos debe hacerse principalmente desde el principio de calidad, no desde el principio de consentimiento, que implica un automatismo acrítico, ni tampoco desde el principio de información porque conllevaría la implantación de soluciones básicamente burocráticas $^{51}$. El principio de calidad, que es el más importante dentro del contenido esencial del derecho fundamental a la protección de datos personales en los ámbitos donde hay excepciones al consentimiento ${ }^{52}$, alberga dentro de sí: el principio de adecuación y prohibición de

50 El TJCE, en la Sentencia Lindqvist ha señalado que las previsiones de la Directiva 95/46/CE no suponen, en sí mismas, una restricción contraria a la libertad de expresión o de otros derechos fundamentales y que corresponde a las jurisdicciones nacionales ponderar en cada supuesto de conflicto qué derecho debe primar.

51 La Sentencia de la Audiencia Nacional, de 12 de enero de 2001, al analizar la relación entre los arts. 18.4 y $20 \mathrm{CE}$, señala que: "pese a la carencia de regulación específica, la mejor doctrina entiende que visto el contenido del art. 6.1 de la LORTAD [...] la expresión salvo que la Ley disponga otra cosa permite entender que no es necesario el consentimiento del afectado, cuando el art. 20 del CE permite el tratamiento. Lo que exigirá una ponderación del caso concreto y desde los principios de adecuación, pertinencia y congruencia recogidos en el artículo 4 de la LOPD". Cfr. también las Sentencias de la Audiencia Nacional, de 2 de febrero de 2006 y de 16 de marzo de 2006; Lesmes (año, pp. 199-202).

Cfr. Troncoso (2010, pp. 341-394) exceso, que exige que los datos que se publiquen sean idóneos y pertinentes para la finalidad periodística y que no se publiquen datos excesivos, evitando que la libertad de expresión se ejerza de una manera desmesurada y exorbitante que no sirva para el debate político ${ }^{53}$; el principio de finalidad legítima, que demanda que los tratamientos de datos personales tengan exclusivamente fines periodísticos o de expresión artística o literaria, teniendo que guardar las intromisiones en la protección de datos congruencia con la finalidad de formación de la opinión pública libre, que es lo que justifica su protección preferente ${ }^{54}$; el principio de exactitud de la información, que obliga a que esta sea veraz, y a rectificar y cancelar los datos erróneos o inexactos, algo especialmente aplicable a la publicación de medios de comunicación en Internet, teniendo en cuenta la permanencia de la información y su fácil localización a través de los

53 Esto ocurre cuando se publican datos íntimos, expresiones injuriosas o vejatorias, datos que no sean veraces, datos de menores, etc.. Así, muchas veces se publican datos personales cuando el interés público se alcanza igualmente publicando un menor número de datos o anonimizando o disociando la información personal -eludiendo la divulgación de datos de menores que han sufrido abusos, evitando que en las fotografías aparezcan carteles con teléfonos, pixelando las imágenes, etc.-. En muchas ocasiones, el tratamiento de datos es excesivo para la finalidad. Así, la Sentencia de la Audiencia Nacional, de 9 de julio de 2009, estima un recurso interpuesto contra una Resolución de archivo de la AEPD, que había considerado prevalente la libertad de información sobre la protección de datos personales en un supuesto de publicación de imágenes de enfermos: "aunque las imágenes no sean de buena calidad, puede entenderse que el tratamiento del dato de la imagen ha sido excesivo tomando en consideración que no se encuentra amparado por el consentimiento de los afectados (no consta que conocieran la publicación de las imágenes) y tampoco se encuentra amparado por la libertad de información y, en todo caso, parece que se ha producido un empleo desmedido de la imagen como dato personal puesto que el carácter noticiable de la información se cumplía suficientemente sin necesidad de incluir imágenes directas de los enfermos". Las exigencias del principio de adecuación y prohibición de exceso se refieren a la publicación de la información pero no impiden estos tratamientos de datos antes de que la información sea publicada.

54 Sin embargo, hay elementos del principio de finalidad, como la determinación, la explicitud o el respeto a la finalidad originaria en todas las fases del tratamiento que no son aplicables a estos supuestos. 
buscadores ${ }^{55}$. El principio de calidad explica mejor la jurisprudencia constitucional que pondera la libertad de información y la privacidad y que es aplicable claramente en este ámbito ${ }^{56}$. Así, la

$55 \quad$ No nos podemos detener ahora en la problemática de que los medios de comunicación manipulen o retoquen fotografías de los afectados y cuál es su relación con el principio de exactitud de los datos y la necesidad del consentimiento del interesado.

56 Como es sabido, la libertad de información tiene que respetar el derecho a la intimidad de las personas y el derecho fundamental a la protección de datos personales. Nuestra jurisprudencia constitucional ha fijado una serie de criterios que son útiles en la delimitación entre la libertad de información y el derecho a la intimidad y que sirven también para la protección de datos personales. Para que prevalezca la libertad de información es necesario que lo difundido o que los datos personales objeto de tratamiento por el medio de comunicación sean de interés público, es decir, tengan un carácter noticiable, bien en razón del objeto -porque su contenido resulte de interés colectivo o general-, bien por el sujeto -por la relevancia y dimensión pública de la persona objeto de la información-. Un asunto tiene relevancia pública porque su conocimiento sirve al interés general al referirse a un acontecimiento o a una cuestión que es objeto de controversia social que afecta a los ciudadanos en general y no solo a unos particulares. Hay personas que por su profesión o cargo público se encuentran en el escenario público y están sometidas por ello a la crítica y a un nivel de escrutinio público superior al de una persona anónima -cfr. SSTC 171/1990, de 12 de noviembre y 204/1997, de 25 de noviembre-. No obstante, la libertad de información también tiene límites. Las personas sobre las que hay un interés del público, por el cargo que ostentan o por la profesión que realizan, mantienen un grado de derecho a la intimidad. Además, la información debe ser veraz, lo que a juicio del Tribunal Constitucional -Sentencia 61/2004, de 19 de abril, implica que el informador haya realizado una labor de indagación con la diligencia que le es exigible a un profesional-. Asimismo, las informaciones vertidas en los medios no pueden incluir expresiones injuriosas, vejatorias $\mathrm{o}$ insultos sin relación con las ideas u opiniones que se expongan y que resulten innecesarias para su exposición -la STC 104/1986, de 17 de julio-.Cfr. más ampliamente Carrillo (2003, pp. 25-37 y 77-91).

La Agencia Española de Protección de Datos ha aplicado alguno de estos criterios elaborados por la jurisprudencia constitucional para delimitar la libertad de información del derecho a la intimidad. La Resolución $775 / 2007$-donde curiosamente se mantiene un concepto más amplio de medio de comunicación- archivó la denuncia contra Esquerra Unida del País Valencià por publicar datos de nombre, apellidos, puesto laboral que ocupaba en el Ayuntamiento de Paiporta, así como las retribuciones que cobraba por desempeñar dicho puesto. Esta información se publicó tanto en la web del partido político como en un boletín informativo. La Agencia Española entiende: "en primer lugar, que la información publicada era veraz, puesto que los datos que fueron asociados al nombre y apellidos del denunciante coinciden con los datos que figuran en los Presupuestos Anuales del Ayuntamiento de Paiporta. En segundo lugar, la información publicada tenía una indudable trascendencia pública y social para la localidad de Paiporta, al publicar datos sobre el incremento extraordinario que había efectuado el Ayuntamiento de Paiporta a las retribuciones correspondientes al puesto que se había adjudicado al denunciante, reciente ex-concejal del citado Ayuntamiento, por tanto dicha información no fue publicada con la intención de desacreditar al denunciante, sino únicamente en el mayoría de los criterios para la ponderación de derechos -el interés público por razón del sujeto o del objeto, la veracidad o exactitud de la información, la esencialidad de la información, la sensibilidad de los datos, etc. - tienen cabida

ejercicio legítimo de informar a los ciudadanos sobre los asuntos de mayor trascendencia o notoriedad, como parte de sus funciones de partido político y para contribuir a la formación de una opinión pública en torno a los asuntos de interés local. En consecuencia, del análisis efectuado de la información publicada en el boletín y en la página Web de ESQUERRA, se desprende que ésta era veraz, tenía indudable trascendencia pública en la localidad de Paiporta y fue publicada dentro del ejercicio de sus funciones como partido político y con la finalidad de contribuir a la formación de una opinión pública, por lo que de acuerdo a los criterios de la doctrina expuesta, en este caso concreto, prevalecería el derecho fundamental a la información recogido en el artículo 20 de la Constitución Española sobre el derecho fundamental a la protección de los datos personales establecido en el artículo 18.4 de dicha Constitución. Por ello, de acuerdo a las anteriores consideraciones, procede estimar las alegaciones efectuadas por ESQUERRA y el archivo de la infracción del artículo 6.1 de la LOPD, que se imputaba en el presente procedimiento sancionador". Igualmente, la AEPD en la Resolución 598/2007 resolvió una tutela del derecho de cancelación alegando la STC 107/1998, que concreta que "el valor preponderante de las libertades públicas del art. 20 de la CE, en cuanto se asienta en la función que éstas tienen de garantía de una opinión pública libre indispensable para la efectiva realización del pluralismo político, solamente puede ser protegido cuando las libertades se ejerciten en conexión con asuntos que son de interés general por las materias a que se refieren y por las personas que en ellos intervienen y contribuyen, en consecuencia, a la formación de la opinión pública, alcanzando entonces su máximo nivel de eficacia justificadora frente al derecho al honor, el cual se debilita, proporcionalmente, como límite externo de las libertades de expresión e información, en cuanto sus titulares son personas públicas, ejercen funciones públicas o resultan implicadas en asuntos de relevancia pública, obligadas por ello a soportar un cierto riesgo de que sus derechos subjetivos de la personalidad resulten afectados por opiniones o informaciones de interés general, pues así lo requieren el pluralismo político, la tolerancia y el espíritu de apertura, sin los cuales no existe sociedad democrática". La AEPD ha recogido esta jurisprudencia constitucional relativa a la libertad de información y el derecho a la intimidad para resolver distintas Resoluciones. En su Resolución de 24 de febrero de 2009 cita la jurisprudencia del TC en la que se tiende a "otorgar una posición preferente a la libertad de expresión frente a otros derechos constitucionales, siempre y cuando los hechos comunicados se consideren de relevancia pública (STC 105/1983, STC 107/1988) y atendiendo a la veracidad de la información facilitada (STC 6/1988, STC 105/1990, STC 240/1992)." Y en función de lo anterior, concluye que, por todo ello, cabe proclamar que un ciudadano que no goce de la condición de personaje público ni sea objeto de hecho noticiable de relevancia pública tiene que resignarse a soportar que sus datos de carácter personal circulen por la red sin poder reaccionar ni corregir la inclusión ilegítima de los mismos en un sistema de comunicación universal como Internet". Esta cita proviene de la Resolución de 7 de abril de 2008 y se encuentra, también en la Resolución de 24 de febrero de 2010. Todas las Resoluciones se encuentran publicadas en https://www.agpd.es/portalwebAGPD/resoluciones/archivo_actuaciones/index-ides-idphp.php y han sido analizadas por Cazurro (año, pp. 89-246). 
dentro del principio de calidad. Hay temas que por ser de interés público pueden ser difundidos y pueden justificar la recogida y tratamiento de datos personales, aunque afecten a la intimidad de las personas o aunque supongan un límite a su derecho a controlar su información personal. La persona no puede oponerse a la publicación de esa información o al tratamiento de sus datos personales por el medio de comunicación, aunque afecten al ámbito privado. No hay que proteger los datos íntimos de una persona de relevancia pública cuando existe interés público, especialmente, cuando su comportamiento privado contrasta con su discurso público -por ejemplo, las fotos de las fiestas privadas de BerIusconi- y esto puede ser valorado por la opinión pública, ser criticado y favorecer el cambio político -algo esencial en el valor procedimental de la libertad de información- ${ }^{57}$.

57 En todo caso, incluso en relación con los personajes públicos existen tratamientos de datos que pueden suponer una publicación excesiva. La intimidad de los personajes públicos debe ser respetada si los datos tratados no tienen relevancia con su función pública y no son imprescindibles para favorecer la libertad de información y la opinión pública libre -creencias, datos de salud, orientación sexual-, no existiendo un interés público que justifique la publicidad. El Decreto Legislativo, de 30 de junio de 2003, que aprueba en Italia el Codice in materia di protezione dei dati personali -Codice Della Privacy-recoge la excepción del consentimiento para que los periodistas traten datos especialmente protegidos, siempre que se cumpla la esencialidad de la información en relación con los acontecimientos de interés público (art. 137.2).

Hay que recordar que el Defensor del Pueblo Europeo ha manifestado que "no debería hacerse referencia a la protección de datos cuando, por ejemplo, las personas están actuando en calidad pública, cuando participan en un proceso de toma de decisiones público por propia iniciativa o cuando intentan influir en dicha toma de decisiones". Cfr. la Carta del Defensor del Pueblo Europeo al Presidente de la Comisión, de 30 de septiembre de 2002, y el documento Openness and data protection en http://ombudsman.europa.eu/. No obstante, el Grupo del Artículo 29 en su Dictamen 3/1999, de 3 de mayo, relativo a la "Información del sector público y protección de los datos personales" -"Contribución a la consulta iniciada con el Libro Verde de la Comisión Europea titulado La información del sector público: un recurso clave para Europa“, COM (1998)585- señala que "el legislador, cuando desea que un dato se vuelva accesible al público no considera sin embargo que haya que convertirse en res nullius. Tal es la filosofía del conjunto de nuestras legislaciones. El carácter público de un dato de
Que el principio de calidad sea el que mejor explica la necesidad de conciliar el derecho a la protección de los datos de carácter personal con la libertad de expresión no encubre que la ponderación en cada caso concreto no sea una actividad fácil. Es necesario analizar pausadamente cada supuesto de hecho porque hay casos claros pero también abundantes hard cases, y muchos más habrá con el reconocimiento abierto del derecho al olvido en Internet en la propuesta de Reglamento, lo que incrementará de manera exponencial las reclamaciones al responsable del tratamiento. Es necesario valorar en cada caso que el tratamiento de datos personales se haya efectuado "exclusivamente" con fines periodísticos o de expresión literaria o artística; que todos los datos publicados tienen interés público y son necesarios para una opinión pública libre y no se trata de un "mero interés público" -expresión de la curiosidad de una amplia parte de la sociedad, que no legitima ninguna intromisión en ningún derecho fundamental y que no tiene nada que ver con el auténtico interés público, como elemento objetivo que define la importancia de una información en Internet ${ }^{58}$-; que la información es veraz y que con carácter previo a su difusión se ha llevado a cabo una labor diligente de indagación; que las expresiones sobre las personas, aun siendo hirientes, molestas o desabridas, no son injurio-

carácter personal, resulte de una normativa o de la voluntad de la propia persona a la que alude el dato, no priva, ipso facto y para siempre, a dicha persona de la protección que le garantiza la ley en virtud de los principios fundamentales de defensa de la identidad humana". Cfr. el documento en http://ec.europa.eu/justice_home/fsj/privacy/policy_papers/policy_papers_topic_en.htm\#public_registers Esto obliga a llevar a cabo una ponderación y a aplicar el principio de proporcionalidad, una cuestión que hemos abordado en otro momento (Troncoso, 2010, pp. 729-731 y 781-796).

58 Cfr. Arias (2010). 
sas o vejatorias; que se respeta al menos el grado de intimidad mínima que merecen las personas sobre las que hay un interés del público, por el cargo que ostentan o por la profesión que realizan; etc. Lógicamente, no basta con afirmar la necesidad de conciliar la libertad de expresión con el derecho a la protección de datos personales sino que es necesario que alguien vele porque esta conciliación se produzca. La aplicación del generoso régimen de excepciones a los tratamientos de datos personales en Internet, con fines periodísticos o de expresión artística o literaria, no puede dar lugar a la indefensión de los interesados o a la percepción de que en este ámbito ni la legislación ni los derechos prevalecen. No es fácil que esta función de ponderación en toda su variedad de matices la puedan cumplir las Agencias de Protección de Datos, tal y como están configuradas actualmente, más habituadas a la adopción de decisiones automáticas cuando no automatizadas en virtud de la existencia o no de una habilitación legal ${ }^{59}$. Tampoco parece una cuestión clara que sea la Agencia de Protección de Datos, que no deja de ser una Administración Pública -aunque independiente-, pueda tener competencias para limitar el ejercicio de un derecho fundamental tan importante para una sociedad democrática como es la libertad de expresión e información. Esto no se deduce de la LOPD que atribuye a la Agencia la función de velar por el cumplimiento de

59 Habitualmente la AEPD ha otorgado prevalencia a la libertad de expresión e información sobre el derecho a la protección de datos personales en relación con la relevancia pública de los asuntos, y negándosela cuando un ciudadano "no goce de la condición de personaje público ni sea objeto de hecho noticiable de relevancia pública", sin incidir en otras cuestiones como la veracidad o la ausencia de expresiones vejatorias o insultantes, y sin interesarse en si el tratamiento es excesivo o se podía alcanzar la finalidad legítima disociando la información. la legislación de protección de datos personales (art. 37.a), sin hacer mención alguna a la libertad de expresión y de información ${ }^{60}$. Esta cuestión se deja claramente abierta en la propuesta de reglamento que incluye dentro de las excepciones a los tratamientos de datos personales con fines periodísticos o de expresión literaria o artística lo relativo a las autoridades de control independientes y a la cooperación y coherencia. Es necesario, en este punto un pronunciamiento claro del legislador nacional, al que se remite en este punto la propuesta de Reglamento. Sí parece claro que la responsabilidad última de la aplicación de las excepciones a los tratamientos de datos con fines periodísticos o de libre expresión literaria o artística y de la conciliación de los derechos en presencia le corresponde a los órganos jurisdiccionales ${ }^{61}$. También, parece meridianamente claro en la propuesta de Reglamento que esta labor de ponderación no la puede hacer los motores de búsqueda.

La publicación de los medios de comunicación en Internet, así como la existencia de los buscadores, hace que se produzca una intromisión continuada en los derechos de las personas. Como se ha señalado ya, el responsable del tratamiento principal es el medio de comunicación que publica la información en Internet y que se encuentra amparado por el ejercicio de la libertad de información (art. 20 CE), o la persona que lleva a cabo los tratamientos de datos

60 Carrillo (año, p. 50) señala que las restricciones al derecho a la intimidad deben ser adoptadas por la autoridad juridicial, si bien ésta no es una prescripción que se derive del artículo 18.1 CE, por lo que también podrán ser acordadas por autoridades administrativas, siempre que para ello exista una habilitación legal.

61 Cfr. la SJUE, de 16.12.2008, as. Satakunnan Markkinapörssi y Satamedia y la Sentencia Lindquist. 
personales con fines periodísticos o de expresión literaria o artística, utilizando la expresión en un sentido amplio que da el Considerando 121 de la propuesta de Reglamento. Por tanto, la responsabilidad de lo que se publica es del medio de comunicación -o de la persona que lleva a cabo el tratamiento en ejercicio de la libertad de expresión-, no del buscador. Por ello, no parece razonable atribuir la responsabilidad de las posibles infracciones al buscador que se limita a localizar la información que los medios de comunicación -que, al igual que los diarios oficiales, son fuente accesible al público ex art. 3 LOPD- publican en Internet al mismo tiempo que se exonera al medio de comunicación, protegido por la libertad de información. La LOPD señala expresamente que el carácter de fuente accesible al público implica que la consulta puede ser realizada por cualquier persona, autorizando el tratamiento y la cesión sin consentimiento (arts. 6.2 y 11.2.b). Además, como ya se ha analizado, la propuesta de Reglamento establece que cuando el responsable del tratamiento haya autorizado a un tercero a publicar datos personales -y lo ha autorizado cuando lo publica en un medio de comunicación, que tiene el carácter de fuente accesible al público o cuando no implanta ningún mecanismo que evite la indexación y la difusión masiva-, será considerado responsable de esta publicación (art. 17.2) ${ }^{62}$. Hay que tener en cuenta, además, que mientras que la publicación de datos personales en diarios oficiales o webs institucionales o en relación con las personas que pertenezcan a grupos pro-

62 La responsabilidad de quien lleva a cabo la publicación -medio de comunicación, diario oficial-y de los buscadores se ha analizado en el apdo. 1. fesionales no supone el ejercicio de un derecho fundamental, los tratamientos de datos personales con fines periodísticos o de expresión literaria o artística están amparados por la libertad de expresión. Así, aún en el marco de la LOPD, que reconoce un derecho de oposición frente a los tratamientos de datos personales que provengan de fuentes accesibles al público (ex art. 6.2 $)^{63}$, hay que subrayar que no se encuentra en la misma situación el ejercicio de un derecho de oposición en relación con el tratamiento de datos procedentes de fuentes accesibles al público como pueden ser repertorios telefónicos, listados de personas que pertenecen a grupos profesionales o un eventual censo promocional, donde no se ejercita ningún derecho fundamental -salvo, en su caso, la libertad de empresa, que no tiene una posición preferente en nuestro sistema constitucional-, que el ejercicio del derecho de oposición en relación con los tratamientos de datos personales que llevan a cabo los buscadores y que tienen su origen en los medios de comunicación o en tratamientos con fines periodísticos o de expresión literaria o artística porque estos se encuentran protegidos por el ejercicio de una libertad preferente que es garantía de una opinión pública libre dentro de una sociedad democrática. Hasta ahora, las posibles intromisiones en los derechos de las personas ocasionados por el ejercicio de la libertad de información han sido resueltas por los Tribunales, en virtud de lo previsto en la Ley Orgánica 1/1982 -por la vía preferente y sumaria del amparo civil- y a través de la Ley cho de oposición y de cancelación frente a los buscadores en el apdo. 1 . 
Orgánica 2/1984, de 26 de marzo, reguladora del derecho de rectificación. No parece razonable afirmar que corresponde a los buscadores la limitación de la información que publican los medios de comunicación en Internet, de manera que, a petición de los interesados, tuvieran que limitar la buscabilidad de una información que, además, continua publicándose por los medios de comunicación en Internet. Posiblemente, los buscadores disponen de medios técnicos para no buscar una información relativa a una persona. Sin embargo, sin querer entrar a analizar ahora la naturaleza de Internet, parece esencial que en la Red -que es sobre todo un espacio de libertad- los buscadores sean herramientas neutrales y no establezcan ningún tipo de censura previa. Es un peligro que la herramienta deje de ser neutral, que alguien sea buscado o no sea buscado en función de que lo determine el propio interesado o el buscador ${ }^{64}$.

Así, la libertad de expresión incluye dentro de su contenido la búsqueda, recepción y difusión de ideas a través de Internet. Los buscadores son herramientas indispensables para el libre acce-

64 El concepto de neutralidad de la red se basa en la idea de que la información en Internet debe ser transmitida con imparcialidad, sin tener en cuenta el contenido, el destino o el origen. Existe una "Comunicación de la Comisión Europea sobre neutralidad de la red y una Internet abierta en Europa", de 19 de abril de 2011 (COM (2011) 222 final). El Supervisor Europeo de Protección de Datos ha emitido también un Dictamen sobre la neutralidad de la red, donde incide en que la supervisión por parte de los proveedores de Internet de las comunicaciones de los usuarios puede violar las normas sobre la protección de datos personales y la confidencialidad de las comunicaciones. Así, establece la necesidad de señalar las áreas donde las prácticas de inspección son legítimas, por ejemplo, aquellas necesarias para garantizar la fluidez del tráfico [lo que puede parecer cuestionable, a nuestro juicio, ya que esto puede hacerse disociando la información, además que esta injerencia no superaría el juicio de proporcionalidad en sentido estricto] o por motivos de seguridad; determinar también cuándo dicha supervisión requiere el consentimiento previo de los usuarios, por ejemplo en el caso de la utilización de filtros que tienen como objetivo limitar el acceso a ciertas aplicaciones y servicios, como el llamado "peer to peer". Cfr. el Dictamen en www.edps.europa.eu so a la información. Los ciudadanos tienen por ello un derecho a buscar información en Internet y acceder a ella. Los límites a la libertad de circulación de contenidos en Internet y a la búsqueda de la información también suponen límites a la libertad de expresión y de información. Además, los buscadores no están en condiciones de determinar o no la veracidad, la exactitud, el mayor o menor interés público de la información que se publica en Internet, ya que son solo herramientas de búsqueda de información. Por ello, cualquier reclamación de los ciudadanos por la información que aparece publicada en Internet -incluida la solicitud de cancelación de la publicación de la información- tienen que dirigirla a los responsables de los sitios web, que son también responsables del tratamiento principal, sobre todo cuando este es conocido -es el caso de un medio de comunicación, o como hemos señalado en un apartado anterior, de un boletín oficial o de una página web institucional en Internet de una Administración Pública- ${ }^{65}$.

65 Hay que resaltar también en Argentina el asunto C 7181/2008 I, Miragaya Eduardo Daniel c/ Yahoo de Argentina S.R.L y otras medidas cautelares, de 23 de diciembre de 2008, donde el Fiscal Federal de la Nación pidió a Yahoo y a Google el bloqueo de su nombre y de cualquier tipo de información relativa a su persona a la que se accede a través de sus respectivos portales, ya que manifestaba que al incluir su nombre en el campo de búsqueda "aparecía información deshonrosa, mendaz y temeraria sobre su actividad como Fiscal Federal de la Nación". En este caso, si bien inicialmente el Tribunal accedió a las medidas cautelares, posteriormente dictó una resolución de revocación. Entendió el Tribunal que el responsable principal era conocido se trataba de un medio de comunicación- y debía dirigirse a él: "No se advierte óbice para que el actor dirija su pretensión contra los responsables de esos sitios y eventualmente debata con ellos la veracidado exactitud de las noticias que considera que lesionan su honor, cuestión que Google y Yahoo! no están en condiciones de hacer, habida cuenta de que administran una herramienta de búsqueda de información. En efecto, lo contrario implicaría ejecutar las medidas contra quienes no son los responsables de la concreta información a la que se atribuye consecuencias lesivas para el honor del actor, es decir contra quienes no son los habilitados para contradecir respecto de la materia que se debate en autos".

En cambio, en España, la Agencia Española de Protección de datos, como hemos señalado antes (apdo. 1), ha atribuido la responsabilidad, 
Esta es una cuestión que hemos mantenido tradicionalmente ${ }^{66}$ y que aparece ahora recogida en la propuesta de Reglamento que señala que cuando el responsable haya hecho públicos los

obligando a cancelar la publicación, únicamente a Google y nunca a la Administración General del Estado o al medio de comunicación. Así, en relación con las Resoluciones de tutela de derechos de la Agencia Española de Protección de Datos que obligan a Google España a cancelar la información en sus motores de búsqueda y que han sido recurridas a la Sala de lo Contencioso Administrativo de la Audiencia Nacional, el Auto de 27 de febrero de 2012 de ésta ha planteado una cuestión prejudicial en relación con la actividad de los buscadores como proveedores de contenidos en relación con la Directiva 95/46/CE de Protección de Datos. Así, en relación con la actividad del buscador de la empresa "Google" en Internet consistente en localizar la información publicada o incluida en la red por terceros, indexarla de forma automática, almacenarla temporalmente y finalmente ponerla a disposición de los internautas con un cierto orden de preferencia, cuando dicha información contenga datos personales de terceras personas, plantea la Audiencia Nacional si debe interpretarse una actividad como la descrita comprendida en el concepto de "tratamiento de datos" contenido en el art. 2.b de la Directiva 95/46/CE, lo que obviamente merece una respuesta afirmativa. Igualmente señala si debe interpretarse el artículo 2.d) de la Directiva 95/46/CE, en el sentido de considerar que la empresa que gestiona el buscador "Google" es "responsable del tratamiento" de los datos personales contenidos en las páginas web que indexa -obviamente, como hemos señalado en el texto, el buscador es responsable de sus propios tratamientos, no de los realizados por los medios de comunicación o por la Administración-. En tercer lugar, la Audiencia Nacional pregunta si puede la autoridad de protección de datos, tutelando los derechos contenidos en el art. 12.b) y 14.a) de la Directiva 95/46/CE, requerir directamente al buscador de la empresa "Google" para exigirle la retirada de sus índices de una información publicada por terceros, sin dirigirse previa o simultáneamente al titular de la página web en la que se ubica dicha información -nosotros hemos defendido en el apdo. 1 que hay que dirigirse simultáneamente a ambos-. En cuarto lugar, se pregunta si se excluiría la obligación de los buscadores de tutelar estos derechos cuando la información que contiene los datos personales se haya publicado lícitamente por terceros y se mantenga en la página web de origen-ya hemos respondido en texto que estaría excluida esta obligación porque si el tratamiento de la web máster se encuentra fundamentado en la libertad de expresión se mantiene, también puede mantenerse el del motor de búsqueda-. Por último, en relación con el derecho de cancelación y/oposición y el derecho al olvido se plantea si debe interpretarse que los derechos de supresión y bloqueo de los datos, regulados en el art. 12.b) y el de oposición, regulado en el art. 14.a) de la Directiva 95/46/CE comprenden que el interesado pueda dirigirse frente a los buscadores para impedir la indexación de la información referida a su persona, publicada en páginas web de terceros, amparándose en su voluntad de que la misma no sea conocida por los internautas cuando considere que puede perjudicarle o desea que sea olvidada, aunque se trate de una información publicada lícitamente por terceros -ya hemos señalado que si la publicación se encuentra amparada por la libertad de información y de expresión es lícita, no existiría derecho al olvido en este caso, como aclara el art. 17.3 de la propuesta de Reglamento, tampoco ante los buscadores-.

66 Este planteamiento puede ampliarse en Troncoso (2008, pp. 101 y 112 y 2010 pp. $197-212816-831)$. datos personales, es este el que está obligado a adoptar las medidas razonables -incluidas las técnicas- para informar a los terceros que están tratando dichos datos de que un interesado les solicita que supriman cualquier enlace a estos datos personales, o cualquier copia o réplica de los mismos (art. 17.2), de forma que cualquier ejercicio de derechos tiene que dirigirse al responsable del tratamiento de datos con fines periodísticos o de libertad de expresión, y no al buscador. Ya se ha señalado en otro momento de este trabajo que no parece razonable responsabilizar al buscador por encontrar una información administrativa que se publica en un boletín oficial en Internet y, al mismo tiempo, eximir a la Administración de bloquear la publicidad o de establecer límites a la indexación por buscadores a través de protocolos "NO ROBOT". Quien es capaz de determinar si existe o no un interés público que justifique todavía el mantenimiento de la publicación o la veracidad de un concreto dato no puede ser el robot de Google sino quien ordenó la publicación. No obstante, sí existe una responsabilidad de los buscadores sobres sus tratamientos en su memoria caché - de cancelarlos cuando se haya cancelado la fuente principal-, por lo que existe una responsabilidad compartida entre web máster y buscadores, lo que debe llevar también a buscar soluciones compartidas.

Dicho esto, hay que reconocer que existen determinadas publicaciones en sitios webs en Internet que utilizan la imagen de la persona sin su consentimiento, vulnerando su intimidad o dañando su honor gravemente. Este sería el caso, por ejemplo, de webs que utilizan indebi- 
damente la imagen de una persona, haciendo referencia a actividades relacionas con el mercado del sexo o la pornografía, y que en absoluto estarían amparadas en la libertad de expresión y de información. La protección del derecho al honor, a la intimidad o a la imagen en Internet se complica al publicarse frecuentemente esta información en webs de difícil localización, de forma que es complejo determinar quién es el responsable final del tratamiento de esta información. Los particulares que ven sus derechos vulnerados tienen que dirigirse al portal web que vulnera sus derechos para solicitar la cancelación inmediata de la publicidad de esta información. Pero, al mismo tiempo, pueden dirigirse a los buscadores para solicitar la cancelación de la información que se encuentra en su memoria caché. En ocasiones, los responsables de la web -sobre todo si es conocida- cancelan la publicación de la información. No tendría sentido que la página web principal borrara la información y el buscador siguiera ofreciéndola, por lo que en este caso sí existiría una clara responsabilidad de los buscadores por sus propios tratamientos. Sin embargo, en otras ocasiones, no se puede localizar al responsable de la web o este no cancela la publicación de la información. En ese caso, es razonable que el interesado, sin perjuicio del inicio de las acciones judiciales correspondientes contra el responsable de la web, se dirija al buscador para solicitar que bloquee la publicidad de sus datos personales que aparecen en determinadas webs. Si bien los buscadores son inicialmente reacios a este tipo de acciones que limitan el libre acceso a la información, no obstante tienen que implantar mecanismos de autorregulación y de privacidad en el diseño que permitan bloquear la búsqueda de una información cuando manifiestamente ésta supone una vulneración del derecho al honor, a la intimidad o a la imagen de las personas - por ejemplo, cuando se da publicidad como prostituta a alguien que no lo es-. Así, por ejemplo, Youtube o incluso redes sociales como Tuenti tienen instrumentos de autorregulación, y cuando existe una denuncia relativa a sexo explícito, contenido xenofobo o uso de imagen sin consentimiento retiran esa información de Internet ${ }^{67}$. Lo mismo debe hacer en este caso los buscadores, poniendo límites a la indexación de algunas webs, sin perjuicio del ejercicio de las acciones judiciales por el interesado. Es muy importante, en este punto, la autorregulación de los propios buscadores, que no deben esperar en ocasiones a una resolución judicial mientras se siguen vulnerando derechos. El ciudadano también podrá reclamar como medida cautelar dentro de un procedimiento judicial que el juez dicte una resolución dirigida a la página web principal para que bloquee la publicidad y al buscador para que deje de reproducir esta información.

Los buscadores tienen obligación de acatar las medidas cautelares que establece un juez ${ }^{68}$. Hay que señalar que esta resolución judicial que limita el acceso a la información en Internet

67 Hay que analizar en el ámbito de los tratamientos de datos con fines de libertad de expresión la posibilidad que brinda para la autorregulación la aprobación de códigos tipo. Cfr. TASCÓN LÓPEZ, R., "Los Códigos Tipo para la protección de datos personales", REPD, núm. 7, 2010, pp. 151-181; CAZURRO BARAHONA, V., op. cit. pp. 312-332.

68 Por ejemplo, en Argentina, Google sigue adelante con la publicación cuestionada a pesar de la orden judicial en contra, mientras que Yahoo! acata la resolución, incorporando un texto donde explica que no puede mostrar el link porque existe una medida judicial que así lo impide. 
no vulnera la libertad de información y de expresión, que debe ser compatibilizada con otros derechos también de rango constitucional como la intimidad, el honor o la propia imagen ${ }^{69}$. Tampoco debe entenderse como censura, ya que la información ha podido ser buscada, reproducida, almacenada y difundida libremente. En todo caso, es necesario que la medida cautelar que se establezca sea proporcional. Así, es excesivo impedir todas las búsquedas por un nombre de manera indefinida, ya que esto sí supondría un supuesto de censura previa. Bastaría bloquear aquella información que vulnera derechos, dejando aquella otra que es crítica o desagradable pero respetuosa con el honor, la intimidad o la imagen, ya que en caso contrario sí que se estaría vulnerando la libertad de información y de expresión ${ }^{70}$.

Por ello, es necesario en este punto un pronunciamiento más claro del legislador en nuestro país, que tenga en cuenta que la publicación de los medios de comunicación en Internet y los tratamientos de datos personales por los ciudadanos con fines periodísticos o de expresión literaria o artística incrementan tanto la libertad de información y de expresión y la opinión pública libre; como las posibles vulneraciones

69 Hay que mencionar en Argentina el Expte. n. 67.068 (23.392/07), Mazza, Valeria Raquel c/ Yahoo! de Argentina S.R.L y otros s/medidas precautorias, que llevó el abogado Gustavo Tanús.

70 En el asunto antes citado Miragaya Eduardo Daniel c/ Yahoo! de Argentina S.R.L, donde el Fiscal Federal de la Nación pidió a los buscadores el bloqueo de su nombre y de cualquier tipo de información relativa a su persona, el Tribunal señaló que el estándar de responsabilidad por la difusión de noticias inexactas resulta menos riguroso frente a los funcionarios públicos. Así, a nuestro juicio, la difusión de información relativa a un fiscal general tiene interés público. Tampoco parece razonable prohibir la exhibición de imágenes en Google, ya que se refieren a actos públicos de una persona que ocupa un cargo público. a los derechos de otras personas. Igualmente, es necesario materializar el principio de calidad como principio de exactitud en el ámbito de los medios de comunicación y relacionar el derecho de rectificación de la Ley Orgánica 2/1984, de 26 de marzo, reguladora del derecho de rectificación, con el derecho de rectificación y cancelación de la propuesta de Reglamento -en la actualidad de la LOPD-. La Ley Orgánica 2/1984, de 26 de marzo, mantiene la necesidad de que el director del medio de comunicación publique o difunda íntegramente la rectificación, dentro de los tres días siguientes al de su recepción, con relevancia semejante a aquella en que se publicó o difundió la información que se rectifica, sin comentarios ni apostillas (art. 3), una regulación que estaba pensada para la edición impresa en papel pero no para la edición electrónica y que, lógicamente, no ha previsto la cancelación -en este caso, el bloqueo- de la versión electrónica de estas noticias en Internet si se alcanza una sentencia favorable. A esto se une las dificultades que plantea que una autoridad administrativa de protección de datos personales limite el ejercicio de la libertad de expresión e información. Por ello, es necesaria la aprobación de una legislación que resuelva los conflictos que plantea la publicidad de los medios de comunicación y de los tratamientos de datos personales con fines periodísticos en Internet y su accesibilidad indiscriminada e ilimitada en el tiempo a través de los buscadores. 


\section{Bibliografía}

Aragón, M. (1990). Constitución y democracia. Madrid: Tecnos.

Arenas Ramiro, M. (2006). El derecho fundamental a la protección de datos personales en Europa. Valencia; Tirant lo Blanch, 2006.

arias Máiz, V. (2010). “Una excepción al principio de consentimiento informado no contemplada en el art. 6 LOPD: el uso de datos personales por medios de comunicación", Comentario a la LOPD, Civitas-Thomson Reuters, Cizur Menor.

Carrillo, M. (2003). El Derecho a no ser Molestado. Información y vida privada, Thomson, Aranzadi.

Carrillo, M. (2010). “El derecho al olvido en Internet", El País. 30 de enero de 2010.

Cazurro V. (2012). El principio de calidad en los tratamientos de datos personales en los medios de comunicación, tesis doctoral, Universidad de Valladolid.

Cotino, L., "Datos personales y libertades informativas. Medios de comunicación social como fuentes accesibles al público", Comentario a la $L O P D$, Civitas-Thomson Reuters, Cizur Menor, 2010, pp. 295-322.

De La Serna, N. (1980). "Fuentes accesibles al público" en Comentario a la LOPD, CivitasThomson Reuters, Cizur Menor.
ELY, J. H. (1980) Democracy and distrust. A Theory of Judicial Review. Massachussets: Harvard University Press.

Fernández, S. (1997). El derecho de acceso a los documentos administrativos. Madrid:. Marcial Pons.

Guerrero, C. (2006), El impacto de Internet en el Derecho fundamental a la protección de datos de carácter personal. Madrid: Civitas.

Guichot, E. (2010). Transparencia y acceso a la información en el Derecho Europeo, Sevilla: Editorial Derecho Global, Sevilla.

Heredero, M. (1998). La Directiva Comunitaria de protección de los datos de carácter personal. Madrid: Tecnos,.

Lesmes, C. (coord.). (2008). La Ley de Protección de Datos. Análisis y Comentario de su jurisprudencia. Valladolid: Lex Nova.

Mangas, A. (2008). "Comentario al Artículo 52", en MANGAS MARTIN, A., (dir.), Carta de los Derechos Fundamentales de la Unión Europea, Fundación BBVA, pp. 826-851.

Mestre, J. F. (1993). El derecho de acceso a archivos y registros administrativos. Madrid: Civitas.

Paissan, M. (2003). Privacy e giornalismo, Garante per la protezione dei dati personali.

Pomed, L. S. (1989). El acceso de los ciudadanos a los archivos y registros administrativos. Madrid: INAP. 
Puente, A., "Ámbito de aplicación y principios. Responsable y encargado. Derechos. Ficheros específicos. FAQs", en http://www.agpd.es/portalwebAGPD/jornadas/1_sesion_abierta/.

Simón, P. (2012). El régimen constitucional del derecho al olvido digital. Valencia: Tirant lo Blanch

Tascón, R. (2010). “Los Códigos Tipo para la protección de datos personales", REPD, núm. 7 pp. 151-181.

Téllez, A. (2002). La protección de datos en la Unión Europea. Divergencias normativas y anhelos unificadores. Madrid: Edisofer.

Troncoso, A. (dir.). (2008). Transparencia administrativa y protección de datos personales. Madrid: Civitas-APDCM.

Troncoso, A. (2000). "Método jurídico, interpretación constitucional y principio democrático", en Espín, E., y Díaz, F. J., La justicia constitucional en el Estado democrático. Valencia: Tirant lo Blanch.
Troncoso, A. (2010). "El principio de calidad", en Comentario a la LOPD, Civitas-Thomson Reuters, Cizur Menor.

Troncoso, A. (2012). "Hacia un nuevo marco jurídico europeo de protección de datos personales", en Revista Española de Derecho Europeo, núm. 43, pp. 25-160.

Troncoso, A. (2010). La protección de datos personales. En busca del equilibro. Valencia: Tirant lo Blanch.

Villaverde, I. (2010). "El derecho de oposición", en Comentario a la LOPD, Civitas-Thomson Reuters, Cizur Menor.

Villaverde, I. (1995). Estado democrático e información. El derecho a ser informado y la Constitución Española de 1978. Oviedo: Junta General del Principado de Asturias.

Villaverde, I. (1995). Los derechos del público. Madrid: Tecnos. 